Revista de Análisis Económico, Vol. 27, № 2, pp. 75-119 (Octubre 2012)

\title{
UN GRAN VAR BAYESIANO PARA LA ECONOMIA CHILENA
}

\author{
LARGE BAYESIAN VAR FOR THE CHILEAN ECONOMY
}

\section{WILDO GONZALEZ P.*}

Gerencia de Análisis Macroeconómico, Banco Central de Chile

\begin{abstract}
This article develops a Large Bayesian VAR with more than 100 variables for the Chilean economy, as Banbura, Giannone and Reichlin (2010) shows that, when the degree of shrinkage is set in relation to the cross-sectional dimension of the sample (bayesian shrinkage), the forecasting performance of a VAR can be improved by adding macroeconomic variables and sectoral information. The results show that the large bayesian VAR compares favorably with some univariate models. It further examines the impulse response functions to a monetary shock, as well as some sectoral shocks.
\end{abstract}

Keywords: Bayesian VAR, forecasting, bayesian shrinkage, large cross-sections.

JEL Classification: $C 11, C 13, C 33, C 53$.

\section{Resumen}

Este artículo desarrolla un gran VAR bayesiano con más de cien variables para la economía chilena, en el mismo sentido que Banbura, Giannone y Reichlin (2010) se muestra que cuando el grado de contracción del ajuste de los priors son fijados en relación a la dimensión del corte transversal

* Agradezco los valiosos comentarios de un árbitro anónimo, a Eliana González del Banco de la República de Colombia y a los participantes en la XVI Reunión de la Red de Investigadores 2011 del CEMLA. También se aprecia la gentiliza de Marta Banbura y Lucrezia Reichlin. Las exenciones habituales aplican, por lo que las opiniones vertidas en este documento son de mi exclusiva responsabilidad y no comprometen la visión del Banco Central de Chile. E-mail: wgonzale@ bcentral.cl 
de la muestra (bayesian shrinkage), la capacidad predictiva de un VAR puede ser mejorado agregando variables macroeconómicas e información sectorial. Los resultados muestran que la predicción del gran VAR bayesiano se compara favorablemente con relación a algunos modelos univariados. Se examinan adicionalmente los impulsos respuesta a un shock monetario, así como también de algunos shocks sectoriales.

Palabras Clave: VAR bayesiano, pronóstico, shrinkage bayesiano, corte transversal de gran tamaño.

Clasificación JEL: C11, C13, C33, C53.

\section{INTRODUCCION}

Los bancos centrales se enfrentan con el problema de la identificación del impacto macroeconómico de una amplia gama de shocks. Por lo general, estos impactos se estiman utilizando vectores autorregresivos (VAR) o modelos dinámicos de equilibrio general (DSGE). Estos modelos comúnmente contienen un máximo de veinte variables macroeconómicas, esto es un número muy pequeño en relación con la información que se monitorea en la mayoría de los bancos centrales. La justificación de la utilización de sólo un pequeño subconjunto de la información disponible en un DSGE es que los microfundamentos que subyacen en estos modelos aún no están lo suficientemente preparados para incorporar todas las variables (y los shocks) que pueden ser de interés para los bancos centrales, tales como la confianza empresarial, la producción sectorial y los precios de todos los sectores de la economía. Por otro lado, la justificación de la utilización de sólo un pequeño subconjunto de la información disponible en los VAR's es que estos modelos pierden grados de libertad al incluir más variables, en el llamado problema de dimensionalidad.

La literatura sobre modelos de factores ha tratado de resolver este problema, permitiendo la descomposición de grandes paneles de datos en un pequeño número de factores comunes (Stock y Watson (1999); Forni et al. (2000); Stock y Watson (2002); Forni et al. (2005)). También estos métodos se han combinado con las técnicas estándares de un VAR para identificar los efectos de la política monetaria en un gran número de variables (Bernanke, Boivin y Eliasz (2005); Stock y Watson (2005); Boivin y Giannoni (2008)).

En la más reciente literatura empírica existen dos alternativas para el uso de los modelos de factores dinámicos. Uno es aquel en el cual los modelos de factores son usados en una gran base de indicadores económicos, tal como lo hicieron Angelini et al. (2008) para la Zona Euro y Aguirre y Céspedes (2004) para Chile. La otra alternativa consiste y se sustenta en una revisión previa de los datos, esta se basa en una percepción o noción de cuáles pueden llegar a ser los indicadores que más puedan estar relacionados a la variable en que uno está interesado en proyectar. Esta última línea de investigación ha sido seguida por 
Echavarría y González (2011) para Chile, Camacho y Pérez-Quiroz (2009) para España y Camacho y Pérez-Quiroz (2010) y Frale et al. (2008) para la Zona Euro, pero la contribución más notable radica en Mariano y Murasawa (2003), los cuales siguiendo a Stock y Watson (1988) realizan una revisión previa de variables que mejor representan la contabilidad nacional, tomando indicadores que de alguna manera capturen los efectos que tienen sobre el ingreso, oferta y demanda.

Respecto a lo controversial que pueda resultar el hecho de utilizar una gran base de datos versus un pequeño factor dinámico, Boivin y Ng (2003) mencionan que las propiedades asintóticas de los modelos de factores dinámicos a gran escala están lejos de mantenerse en aplicaciones empíricas, estos examinan los pros y los contras empíricos de pronosticar con un gran versus pequeño modelo de factor. El resultado principal de esta línea de investigación resulta que en aplicaciones empíricas a mayor número de series, mayor es la correlación con el factor idiosincrático, lo cual puede sesgar los resultados del factor común.

Recientemente, otro enfoque para resolver el problema de la dimensionalidad se ha explorado en el contexto de la regresión bayesiana. De Mol, Giannone y Reichlin (2008) muestran que el pronóstico bayesiano basado en estimaciones punto converge al pronóstico óptimo, siempre y cuando el ajuste del prior (el grado de contracción) aumente al incrementarse el número de variables. Banbura, Giannone y Reichlin (2010) aplican este resultado a un gran VAR bayesiano (BVAR) con los priors de Litterman (1986) y la suma de coeficientes, Doan, Litterman y Sims (1984). Banbura, Giannone y Reichlin (2010) encontraron que la capacidad de pronóstico y la respuesta al impulso de un shock de política monetaria de su gran modelo, se comparan favorablemente con las de un VAR a menor escala. En tanto, Bloor y Matherson (2008), con datos de Nueva Zelanda, obtienen buenos resultados respecto al desempeño del pronóstico así como también en la transmisión de shock de política monetaria y sectorial.

Los modelos de factores y los enfoques bayesianos pueden desempeñar buenas labores de pronóstico y son capaces de proveer impulsos respuesta a un gran rango de shocks, volviéndose muy útil dentro del toolkit de los macroeconomistas. Sin embargo, una ventaja potencial del enfoque bayesiano sobre los modelos de factores es que la estimación e inferencia pueden ser realizadas en niveles (no estacionarios). En contraste, los modelos de factores trabajan con datos que típicamente tienen que ser transformados con el objeto de lograr la estacionariedad, destruyendo de esta forma la potencial influencia de largo plazo y las posibles relaciones de cointegración que puedan llegar a existir.

Por lo general, nos encontramos que nuestro gran VAR bayesiano proporciona una buena descripción de los datos de Chile, realizando relativamente buenos pronósticos del indicador de actividad económica (IMACEC), inflación (IPC) y tasa de política monetaria (TPM) en comparación con una serie de otros modelos de series de tiempo. Se examinan adicionalmente los impulso respuesta del gran VAR bayesiano a un shock de política monetaria, se encuentran resultados que parecen ser razonables. A fin de poner de relieve la utilidad de los gran VAR's bayesianos, también se introduce una breve mirada en su respuesta sectorial al shock monetario y a uno proveniente de un aumento inesperado en el retorno de la bolsa. 
El trabajo se organiza de la siguiente manera. La Sección 2 describe el marco del VAR bayesiano y el algoritmo de Banbura, Giannone y Reichlin (2010) para la determinación del grado de ajuste del prior bayesiano. La Sección 3 describe brevemente los datos, las especificaciones y el modelo, y en la Sección 4 se describen los resultados de los pronósticos. Los impulsos respuesta se discuten en la Sección 5, y llegamos a la conclusión en la Sección 6.

\section{METODOLOGIA}

\subsection{VAR bayesiano}

Sea $Y_{t}=\left(y_{1, t}, y_{2, t}, \ldots, y_{n, t}\right)^{\prime}$ un set de series de tiempo. La representación de estas en un $\operatorname{VAR}(\mathrm{p})$ es igual a:

$$
Y_{t}=c+A_{1} Y_{t-1}+\ldots+A_{p} Y_{t-p}+u_{t}
$$

donde $c=\left(c_{1}, c_{2}, \ldots, c_{n}\right)^{\prime}$ es un vector n-dimensional de constantes, $A_{1}, \ldots ., A_{p}$ son matrices autorregresivas de $n \times n$, y $u_{t}$ es un proceso ruido blanco n-dimensional con una matriz de covarianzas $E u_{t} u^{\prime}=\Psi_{t}$.

Los priors de Litterman (1986), siempre referidos como los priors de Minnesota, sugieren que todas las ecuaciones están centradas alrededor de un camino aleatorio con drift:

$$
Y_{t}=c+Y_{t-1}+u_{t}
$$

Esto básicamente contrae los elementos de la diagonal $A_{1}$ hacia uno y los otros coeficientes $\left(A_{2}, \ldots ., A_{p}\right)$ hacia cero. Los priors de Litterman también encarnan la creencia de que los rezagos más recientes proveen una mayor información que las más distantes y también que los propios rezagos explican más que los rezagos de otras variables en el modelo.

Los priors son impuestos configurando los siguientes momentos previos de la distribución de los coeficientes:

$$
E\left[\left(A_{k}\right)_{i j}\right]=\left\{\begin{array}{l}
\delta_{i}, \quad j=i, k=1 \\
0, \quad \text { en otro caso }
\end{array} \quad \mathrm{y} \quad V\left[\left(A_{k}\right)_{i j}\right]=\vartheta \frac{\lambda^{2}}{k^{2}} \frac{\sigma_{i}^{2}}{\sigma_{j}^{2}}\right.
$$

Se asume que los coeficientes $A_{1}, \ldots ., A_{p}$ son independientes y tienen una distribución normal. La matriz de covarianza de los residuos se asume diagonal, fija y conocida $\left(\Psi=\Sigma\right.$, donde $\Sigma=\operatorname{diag}\left(\sigma_{1}^{2}, \ldots, \sigma_{n}^{2}\right)$, y el prior del intercepto es difuso. Originalmente, Litterman fija $\delta_{i}=1$ para todo $i$, reflejando la creencia de que todas las variables están caracterizadas por una alta persistencia. Sin embargo, este prior no es apropiado para las variables que uno cree poseen una fuerte reversión a la media, para estos se impone un prior igual a $\delta_{i}=0$. 
El híper parámetro $\lambda$ controla el ajuste general (overall tightness) de la distribución prior alrededor de $\delta_{i}$. Este híper parámetro gobierna la importancia de las creencias relativas a la información contenida en los datos, cuando $\lambda=0$ el posterior es igual al prior, por lo tanto los datos no influencian las estimaciones. En el otro extremo, si $\lambda=\infty$ remueve toda influencia de los priors, siendo los coeficientes equivalentes a las estimaciones de mínimos cuadrados ordinarios (MCO). El factor $1 / k^{2}$ es la tasa a la cual el prior de la varianza decrece con el tamaño del rezado del VAR, y $\sigma_{i}^{2} / \sigma_{j}^{2}$ toma en cuenta las diferencias en escala y variabilidad de los datos. El coeficiente $\vartheta \in(0,1)$ gobierna el grado en que los rezagos de las otras variables son menos importantes que los propios rezagos.

Dentro del contexto del análisis estructural debemos tomar en cuenta la posible correlación entre los residuos de las distintas variables, consecuentemente el supuesto de Litterman de matriz de covarianzas diagonal y fija es algo problemático. Para resolver este problema, seguimos a Kadiyala y Karlsson (1997) y Sims y Zha (1998) e imponemos una distribución Normal para los coeficientes y una distribución Normal inversa Wishart para la matriz de covarianzas de los residuos.

Otra modificación es la propuesta por Doan, Litterman y Sims (1984), que se impone sobre la suma de los coeficientes. Consideremos un VAR en su forma de corrección de errores:

$$
\Delta Y_{t}=c-\left(I_{n}-A_{1}-\ldots-A_{p}\right) Y_{t-1}+B_{1} \Delta Y_{t-1}+\ldots+B_{p-1} \Delta Y_{t-p+1}+u_{t}
$$

La suma de los coeficientes $\left(I_{n}-A_{1}-\ldots-A_{p}\right)$ se ajusta hacia cero. El híper parámetro $\tau$ controla el grado de ajuste de este prior. Así como $\tau \rightarrow 0$ el VAR satisfará el prior, por otra parte altos valores de $\tau$ relajará el prior, cuando $\tau=\infty$, el prior no tendrá influencia sobre las estimaciones del VAR. Es importante notar que la restricción en la suma de los coeficientes implica que existen tantas tendencias estocásticas en el VAR como existen variables I(1). En este sentido, es razonable asumir que existen relaciones de cointegración de largo plazo estables en el sistema. Sims (1993) introduce un prior que permite de alguna manera esta posibilidad. Este prior de "co-persistencia" está gobernado por el híper parámetro $\theta$. Así como $\theta \rightarrow 0$ el VAR incrementalmente satisfará este prior, tal que existe una tendencia estocástica en el sistema $\theta=0$; por otro lado el prior no tiene influencia en las estimaciones del VAR cuando $\theta=\infty$. Juntos, los priors de Minnesota, la Wishart invertida, la suma de los coeficientes y los priors de copersistencia son los que Robertson y Tallman (1999) llaman el prior modificado de Litterman.

Escribiendo el VAR en notación matricial:

$$
Y=X B+U
$$

donde $Y=\left(y_{1}, \ldots, y_{T}\right)^{\prime}, X=\left(X_{1}, \ldots, X_{T}\right)^{\prime}, X_{t}=\left(Y_{t-1}^{\prime}, \ldots, Y_{t-p}^{\prime}, 1\right)^{\prime}, U=\left(u_{1}, \ldots, u_{T}\right)^{\prime}$ y $B=\left(A_{1}, \ldots, A_{p}, c\right)^{\prime}$ es una matriz $k \times n$ conteniendo todos los coeficientes con $k=n p+1$. La forma del prior Whishart inversa es entonces:

$$
\Psi \sim i W\left(S_{0}, \alpha_{0}\right) \quad B \mid \Psi \sim N\left(B_{0}, \Psi \otimes \Omega_{0}\right)
$$


donde los parámetros $B_{0}, \Omega_{0}, S_{0}$ y $\alpha_{0}$ son escogidos para satisfacer nuestras expectativas previas para $B$ y $\Psi$. Una práctica utilizada para la implementación del prior modificado de Litterman es agregar observaciones dummies al sistema (5), agregando $T_{d}$ observaciones dummies, $Y_{d}$ y $X_{d}$ es equivalente a imponer un prior Whishart inverso con $B_{0}=\left(X_{d}^{\prime} X_{d}\right)^{-1} X_{d}^{\prime} Y_{d}, \Omega_{0}=\left(X_{d}^{\prime} X_{d}\right)^{-1}, S_{0}=\left(Y_{d}-X_{d} B_{0}\right)^{\prime}\left(Y_{d}-X_{d} B_{0}\right)$, y $\alpha_{0}=T_{d}-k-n-1$. Agregamos las siguientes observaciones dummies para igualar los momentos de nuestro prior

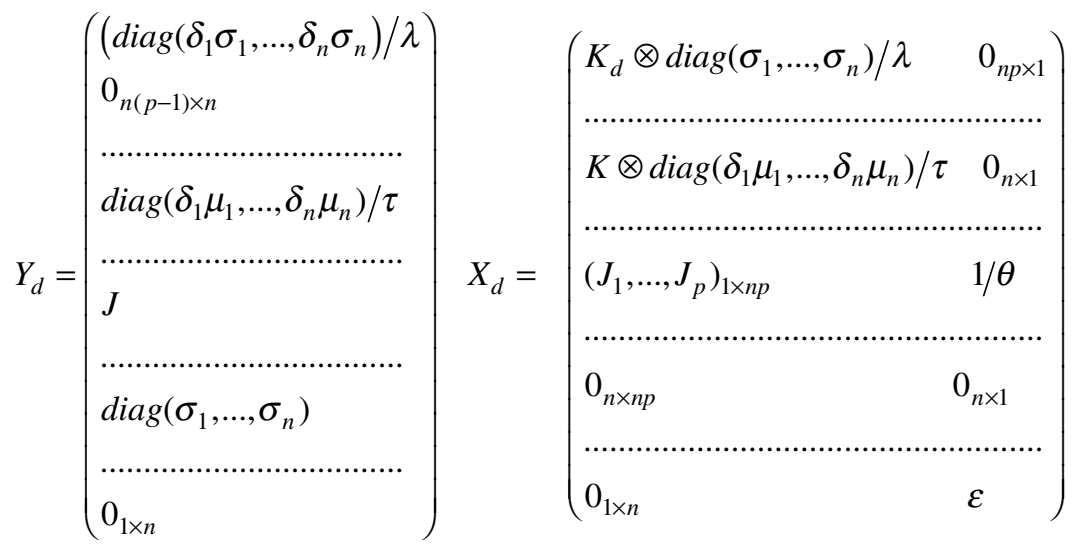

donde $J=\delta_{1} \mu_{1}, \ldots, \delta_{n} \mu_{n} / \theta, \quad K=1, \ldots, p, \quad K_{d}=\operatorname{diag}(K)$ y $\varepsilon$ es un pequeño número. Hablando de manera general, el primer bloque de dummies impone las creencias sobre los coeficientes autorregresivos, el segundo bloque de dummies impone el prior de suma de coeficientes, el tercer bloque impone el prior de co-persistencia y el cuarto y quinto bloque imponen los priors para la matriz de covarianzas y el intercepto. Siguiendo la práctica común, fijamos el prior para el parámetro $\sigma_{i}$ igual a desviación estándar del residuo de una regresión univariada con $p$ rezagos para la variable $y_{i t}$. Igualmente, para el parámetro $\mu_{i}$ (el prior para el promedio del nivel de la variable $\mathrm{y}_{i t}$ ) es fijado igual al promedio de la variable dentro de la muestra.

Aumentando el sistema (5) con las observaciones dummies (7) tenemos:

$$
Y^{*}=X^{*} B+U^{*}
$$

donde $Y^{*}=\left(Y^{\prime}, Y_{d}^{\prime}\right)^{\prime}, X^{*}=\left(X^{\prime}, X_{d}^{\prime}\right)^{\prime}$ y $U^{*}=\left(U^{\prime}, U_{d}^{\prime}\right)^{\prime}$. Después agregamos un prior difuso $\Psi \propto|\Psi|^{-(n+3) / 2}$ (para asegurarnos la existencia de la expectativa del prior $\Psi$ ), el posterior tiene la siguiente forma:

$$
\Psi \mid Y \sim i W\left(\hat{\Sigma}, T_{d}+2+T-k\right) \text { y } B \mid \Psi \sim N\left(\hat{B}, \Psi \otimes\left(X^{*} X^{*}\right)^{-1}\right)
$$

donde $\widehat{B}=\left(X^{*} X^{*}\right)^{-1} X^{*} Y^{*}$ y $\Sigma=\left(Y^{*}-X^{*} \widehat{B}\right)^{\prime}\left(Y^{*}-X^{*} \widehat{B}\right)$. Las observaciones dummies (7) hacen claro que cuando $\lambda, \tau$ y $\theta$ tienden a infinito, el prior de Minnesota, la suma 
de coeficientes y las dummies de copersistencia tenderán a cero y las estimaciones posteriores de los parámetros tenderán a las estimaciones originales de un VAR con MCO.

\subsection{Bayesian Shrinkage}

En un contexto de una regresión clásica aumentar el número de variables deteriora los parámetros estimados. Sin embargo, en un contexto de una regresión bayesiana De Mol, Giannone y Reichlin (2008) muestran que los pronósticos basados en estimaciones punto convergen a un pronóstico óptimo para $n$ y $T$, siempre y cuando el ajuste del prior (el grado de contracción) aumenta a medida que $n$ aumenta. Banbura, Giannone y Reichlin (2010) aplican este resultado a un gran VAR bayesiano con el prior modificado de Litterman, pero sin el prior de co-persistencia, en tanto Bloor y Matherson (2008) aplican este procedimiento con el prior de co-persistencia. Banbura, Giannone y Reichlin (2010) fijan el grado de ajuste del prior usando el siguiente algoritmo:

1. Se seleccionan $n^{*}$ (donde $n^{*}<n$ ) variables benchmark las cuales serán evaluadas dentro de la muestra.

2. Evaluar el ajuste dentro de muestra del VAR estimado con MCO para las $n^{*}$ variables benchmark.

3. Fijar el híper parámetro de la suma de coeficientes $\tau$ de forma proporcional al híper parámetro $\lambda$ que controla el ajuste general (overall tightness) $\left(\tau=\varphi_{1} \lambda\right.$, donde $\left.\varphi_{1} \geq 0\right)$.

4. Escoger el híper parámetro que controla el ajuste general (overall tightness) $\lambda$ $(\mathrm{y} \tau)$ de manera tal que el VAR estimado tenga el mismo ajuste dentro de muestra que el VAR benchmark.

En este trabajo se utiliza el mismo algoritmo para penalizar el sobre ajuste del modelo, pero siguiendo a Bloor y Matherson (2008), tenemos un híper parámetro adicional que necesita ser fijado, este es el prior de co-persistencia $\theta$. Fijamos este híper parámetro de manera que sea proporcional al híper parámetro que controla el ajuste general (overall tightness) $\lambda\left(\theta=\varphi_{2} \lambda\right.$, donde $\left.\varphi_{2} \geq 0\right)$.

Definimos el ajuste dentro de muestra como una medida relativa del error cuadrático medio (ECM) evaluado utilizando el training sample $t=1, \ldots, T-1$. El ECM para la variable i dado un $\lambda$ está dado por:

$$
E C M_{i}^{\lambda}=\frac{1}{T-p-1} \sum_{t=p}^{T-2}\left(y_{i, t+1 \mid t}^{\lambda}-y_{i, t+1}\right)^{2}
$$

donde los parámetros son estimados utilizando el training sample. Las variables están ordenadas de tal forma que las $n^{*}$ variables base están ordenadas primero. El híper parámetro $\lambda$ que controla el ajuste general (overall tightness) para una medida dada de ajuste base (FIT) es buscada en una grilla sobre:

$$
\lambda(F I T)=\arg \min _{\lambda}\left|F I T-\frac{1}{n^{*}} \sum_{i=1}^{n^{*}} \frac{E C M_{i}^{\lambda}}{E C M_{i}^{0}}\right|
$$


donde $E C M_{i}^{0}$ es el ECM de la variable $i$ con prior impuesto exactamente $(\lambda=0)$, y el ajuste base es definido como el promedio relativo ECM de una estimación VAR MCO conteniendo las $n^{*}$ variables base:

$$
F I T=\frac{1}{n^{*}} \sum_{i=1}^{n^{*}} \frac{E M C_{i}^{\infty}}{E M C_{i}^{0}}
$$

\section{DATOS Y ESPECIFICACION DEL MODELO}

El gran VAR bayesiano se estima con datos mensuales que parten en enero de 1996 a diciembre de 2009. Todas las series son ajustadas estacionalmente en forma previa a la estimación. Las series expresadas en porcentaje son la tasa de política monetaria, las tasas de interés y las medidas de riesgo, las demás variables son expresadas en logaritmo. El panel consiste en 116 series que cubren un amplio rango de variables disponibles para la economía chilena, estas categorías incluyen variables externas relevantes, variables relacionadas al sector financiero y variables macroeconómicas.

Dentro de las variables externas se incluyen medidas de precios externos, actividad mundial, condiciones financieras internacionales y precios de commodities (cobre y petróleo). Para las variables financieras locales se utilizan montos reales de colocaciones y tasas de interés promedio de colocaciones (nominal y real), tipo de cambio nominal y real, agregados monetarios y un índice de la bolsa de comercio IGPA.

Las variables macroeconómicas incluidas son las exportaciones e importaciones, que son incluidas como una medida de comercio exterior, desagregación del índice de precios al consumidor con la idea de tratar de capturar las diferencias de los precios relativos y desagregación de variables de los sectores de oferta (IMACEC). Por último, se incluyen variables de seguimiento coyuntural ligadas al comercio, consumo, producción, construcción y mercado laboral. En la Tabla 1 se presenta un resumen de las distintas especificaciones utilizadas (para más detalles de las variables ver el Apéndice 1).

TABLA 1

DISTINTAS ESPECIFICACIONES DEL VAR

\begin{tabular}{|l|c|c|c|c|c|c|c|c|}
\hline Modelo & M1 & M2 & M3 & M4 & M5 & M6 & M7 & M8 \\
\hline VAR simple & $\mathrm{x}$ & $\mathrm{x}$ & $\mathrm{x}$ & $\mathrm{x}$ & $\mathrm{x}$ & $\mathrm{x}$ & $\mathrm{x}$ & $\mathrm{x}$ \\
Variables externas & & $\mathrm{x}$ & $\mathrm{x}$ & $\mathrm{x}$ & $\mathrm{x}$ & $\mathrm{x}$ & $\mathrm{x}$ & $\mathrm{x}$ \\
Condiciones financieras & & & $\mathrm{x}$ & $\mathrm{x}$ & $\mathrm{x}$ & $\mathrm{x}$ & $\mathrm{x}$ & $\mathrm{x}$ \\
Comercio exterior & & & & $\mathrm{x}$ & $\mathrm{x}$ & $\mathrm{x}$ & $\mathrm{x}$ & $\mathrm{x}$ \\
Precios & & & & & $\mathrm{x}$ & $\mathrm{x}$ & $\mathrm{x}$ & $\mathrm{x}$ \\
Sectores de oferta & & & & & & $\mathrm{x}$ & $\mathrm{x}$ & $\mathrm{x}$ \\
Variables de actividad coyuntural & & & & & & & $\mathrm{x}$ & $\mathrm{x}$ \\
Mercado laboral & & & & & & & & $\mathrm{x}$ \\
\hline Nro. de variables & 5 & 11 & 38 & 50 & 58 & 73 & 97 & 116 \\
\hline
\end{tabular}

Fuente: elaboración propia. 
En este caso, el modelo 1 (M1) es el VAR de referencia en la determinación del prior de ajuste bayesiano $(\lambda)$, siendo este similar a un VAR estimado con mínimos cuadrados ordinarios; las variables que incluyen este VAR simple son IMACEC, IPC, IPCX1, TPM y TCR. El modelo 2 (M2) trata de acercarse a las clásicas representaciones de un VAR estimado para una economía pequeña y abierta, como los realizados por Parrado (2001) y Bravo y García (2002). En este al VAR simple de referencia (M1) se incluyen de forma adicional como débilmente exógenas a seis variables externas (M2), estas son la tasa de interés externa (Fed funds), una medida de actividad externa medida por el Baltic Dry Index, una medida de precios externos relevantes para la economía chilena (IPE), junto con el spread corporativo para las economías chilenas, además del precio del petróleo WTI y precio del cobre, estos últimos tienen como objetivo capturar la influencia de los términos de intercambio en la transmisión de shocks externos.

El modelo 3 (M3) trata de capturar la influencia de las variables financieras, y por medio de esto tratar, aunque de manera indirecta, de documentar cuál es la influencia tanto en la transmisión de shocks así como también en el desempeño del pronóstico. En este se incluyen las tasas de colocaciones promedio del sistema financiero tanto en términos nominales como reales, índice de la bolsa de comercio de Santiago (IGPA), algunas medidas de tipo de cambio junto con medidas de agregados monetarios y los montos reales de las colocaciones. Para el caso del modelo 4 (M4) se incluyen las exportaciones y las importaciones, con esto se intenta capturar la influencia del comercio exterior. En el modelo 5 (M5) se incluyen medidas desagregadas muy generales de la descomposición del IPC, con esto se trata de ver si los movimientos entre estos índices mejoran el desempeño del pronóstico tanto en el IMACEC como en el IPC.

Algo poco documentado en la economía chilena es el desempeño de los sectores de oferta en la transmisión de shocks y poco se ha comprobado si estos inducen a una mejora en el pronóstico de la actividad (modelo 6, M6). En Bravo et al. (2003) estudian el impacto desagregado de la política monetaria, siendo su principal conclusión que la transmisión de esta no es diferente a lo que se esperaría considerando los canales de transmisión. Esto, como veremos más adelante, se encuentra en línea con los resultados de nuestro gran VAR bayesiano, aunque el contexto de los resultados entre el trabajo citado anteriormente y este trabajo es diferente. El gran VAR bayesiano se encuentra contenido en el modelo 7 (M7), este constituye una combinación de las 73 variables junto con variables de producción y venta industrial del INE, medidas de ventas de supermercados, ventas minoristas de la CNC, ventas de automóviles, gasto fiscal, ingresos tributarios netos y unas tres medidas del mercado inmobiliario. Por último, en el modelo 8 (M8) se incluyen algunas variables del mercado laboral, estas son la desagregación por sectores de los costos de mano de obra reales y el empleo; con todo esto se tiene un total de 116 variables que tratan de alguna manera de capturar toda la información disponible que pueda ser relevante para el pronóstico de las principales variables macroeconómicas de la economía chilena.

\section{EVALUACION DE PRONOSTICOS}

El siguiente paso consiste en responder la pregunta acerca del grado de bondad del gran VAR bayesiano en el pronóstico de las principales variables; es por ello que 
para evaluar la eficacia de su capacidad predictiva, se procede a realizar proyecciones dinámicas en pseudo tiempo real desde enero del 2005 hasta diciembre del 2009, desde un período en adelante hasta 12 períodos. Con el objeto de contrastar los resultados de las distintas versiones del VAR bayesiano se realizará el mismo ejercicio de proyección para un modelo VAR simple (OLS), un modelo camino aleatorio, ARIMA (AIC) y un ARIMA (BIC) ${ }^{1}$. En cada punto $t$ todos los parámetros son estimados periodo a periodo, con excepción de los priors, que previamente fueron fijados en la muestra antes del periodo de evaluación de proyecciones. Estos fueron fijados siguiendo el algoritmo propuesto por Banbura, Giannone y Reichlin (2010) y modificado por Bloor y Matherson (2008), que en nuestro caso tratamos de minimizar el error de pronóstico relativo del indicador de actividad económica (IMACEC), índice de precios al consumidor (IPC) y la tasa de política monetaria (TPM). El número de rezagos utilizados en el BVAR es igual a seis, Banbura, Giannone y Reichlin (2010) utilizan doce rezagos, mencionando que aún siguiendo algún criterio de información para la determinación de los rezagos, los resultados no diferían de forma significativa; a pesar de esto adicionalmente utilizamos los criterios de información Akaike y Bayesiano (Schwartz - BIC) para la determinación del número de rezagos, pero no encontramos diferencias significativas en el desempeño de los pronósticos.

En la Tabla 2 se presentan los resultados de los errores cuadráticos medios relativos de los VAR's bayesianos con respecto al VAR simple, que nos sirve de referencia para fijar los priors de acuerdo al algoritmo explicado en la Sección 2.2. Además, se reportan los resultados en relación a un modelo camino aleatorio, ARIMA (AIC) y un ARIMA (BIC), sobre los cuales todos los VAR's bayesianos tienen un menor error cuadrático medio.

Sobre los resultados de los VAR's bayesianos, nos encontramos con un resultado que va en línea con lo encontrado por Hendry y Hubrich (2010), que mencionan que agregar información desagregada de una variable para realizar pronósticos de la variable agregada mejora sustancialmente el desempeño de este relativo a pronósticos que no utilizan información desagregada. Esto se refleja claramente en el mejor desempeño del M4 en todos los horizontes en el pronóstico del IMACEC. Conforme se van agregando variables al VAR simple, se observa que las variables externas y las condiciones financieras no aportan a un mejor desempeño fuera de muestra, pero al agregar información sectorial en el M5 mejora fuertemente el desempeño.

El caso opuesto se observa en el IPC, que presenta un mejor desempeño al agregar las variables externas y las condiciones financieras; de ahí en adelante los pronósticos entregados por los distintos modelos no son superiores al VAR simple. Esto ocurre inclusive en el modelo M5 que contiene información desagregada del IPC, este solo parece superar al VAR simple de seis periodos. Sucede lo mismo tomando el IPCX1, que es una medida que excluye alimentos perecibles, combustibles, tarifas reguladas e impuestos específicos. Por último, respecto a la TPM esta parece tener un mejor desempeño en el VAR simple, dando cuenta que para el pronóstico de la TPM no aportan de manera sustancial la información contenida ni en la desagregación del IPC

1 La selección de los modelos ARIMA(d,p,q) se basaron en criterios de información utilizados en la función@bjautofit de Winrats 8.0. 
ni considerando la desagregación del IMACEC, sino más bien importa la evolución de las variables macroeconómicas más importantes.

El siguiente paso consiste en responder la pregunta acerca del grado de bondad de las proyecciones; para verificar si existen ganancias en el pronóstico de los VAR's bayesianos se utiliza el test de Diebold y Mariano (1995) $)^{2}$. Sea $\left\{e_{t}^{i}\right\}_{t=1}^{T}$ el error de pronóstico de modelos alternativos donde $i=$ camino aleatorio, ARIMA (AIC) y ARMA (BIC). Sea $\left\{e_{t}^{b}\right\}_{t=1}^{T}$ los errores de pronósticos de los distintos VAR's bayesianos. El test estadístico es definido como $s=d / \sigma_{d}$, donde $d$ es la media muestral del diferencial de la función de pérdida muestral, $\left\{d_{t}\right\}_{t=1}^{T}$ se obtiene usando $d_{t}=\left(e_{t}^{i}\right)^{2}-\left(e_{t}^{b}\right)^{2}$ para $\mathrm{t}=1,2,3, \ldots, \mathrm{T}$, y donde $\sigma_{d}$ es el error estándar de $d$. El estadístico $s$ se distribuye asintóticamente como una variable aleatoria normal estándar y puede ser estimada con la hipótesis nula de igualdad en la habilidad predictiva $\left(d_{t}=0\right)$. Un valor positivo de $s$ podría sugerir que una forma en particular de los VAR's bayesianos supera a los modelos alternativos en términos del pronóstico fuera de muestra.

Los resultados del test de Diebold y Mariano (1995) se presentan en la Tabla 3. El período de evaluación corresponde a enero del 2005 a diciembre del 2009. En el primer caso que considera el modelo camino aleatorio, los VAR's bayesianos tienen un mejor desempeño fuera de muestra para el IMACEC, IPC e IPCX1, pero no para la TPM. Respecto al modelo ARIMA (AIC) estos son superados para el pronóstico del IMACEC del modelo M4 a M8, pero para el IPC e IPCX1 solo es superado en proyecciones de muy corto plazo hasta tres meses; respecto a la TPM no hay evidencia que las proyecciones VAR bayesiano sean superiores. Por último, respecto a los ARIMA (BIC) son superados en el pronóstico del IMACEC del modelo M4 a M8, para el IPC se observa superioridad notoria de los VAR's bayesianos, pero no para el IPCX1, que solo es superado en un periodo en adelante.

\section{IMPULSOS RESPUESTA}

Para esta sección consideramos principalmente los resultados del impulso respuesta de un shock de política monetaria, adicionalmente también se considera el caso de un shock bursátil en el índice de la bolsa de comercio (IGPA) y un aumento en las primas por riesgo corporativo (Chile). Para la identificación consideramos un esquema de identificación recursivo (Christiano, Eichenbaum y Evans (2005) y Bernanke, Boivin y Eliasz (2005)), para Chile se pueden mencionar los resultados encontrados por Parrado (2001), Bravo et al. (2003), y una revisión más reciente en Jaramillo (2008) y García, González y Moncado (2010). Siguiendo a Bernanke,

2 Es muy importante destacar que la evaluación por medio del test de Diebold y Mariano (1995) se realiza entre los distintos BVAR's y los modelos ARIMA's, por lo que no debería existir el problema de contención de un modelo dentro de otro (especialmente por la parte MA's), este problema si se presentaría en el caso de que la evaluación de los pronósticos sea entre las distintas especificaciones de los BVAR's, lo cual se deja como una futura extensión de este trabajo. 
TABLA 2

ERROR CUADRATICO MEDIO RELATIVO

\begin{tabular}{|c|c|c|c|c|c|c|c|c|c|c|c|c|c|c|c|}
\hline \multicolumn{16}{|c|}{ BVAR(p) respecto a un modelo VAR simple } \\
\hline \multirow{2}{*}{ Horizonte } & \multicolumn{5}{|c|}{ M2 } & \multicolumn{5}{|c|}{ M3 } & \multicolumn{5}{|c|}{ M4 } \\
\hline & IMACEC & IPC & IPCX1 & TPM & TCR & IMACEC & IPC & IPCX1 & TPM & TCR & IMACEC & IPC & IPCX1 & TPM & TCR \\
\hline 1 & 1,02 & 0,93 & 0,98 & 0,99 & 1,05 & 1,17 & 0,85 & 0,92 & 1,15 & 1,05 & 0,96 & 1,11 & 1,13 & 1,56 & 0,95 \\
\hline 2 & 1,05 & 0,92 & 1,00 & 1,01 & 1,18 & 1,10 & 0,88 & 0,99 & 1,05 & 1,20 & 0,95 & 1,04 & 1,17 & 1,49 & 0,92 \\
\hline 3 & 1,07 & 0,94 & 0,96 & 1,04 & 1,29 & 1,12 & 0,93 & 1,04 & 0,92 & 1,39 & 0,94 & 1,04 & 1,21 & 1,47 & 0,90 \\
\hline 4 & 1,07 & 0,95 & 0,91 & 1,06 & 1,40 & 1,11 & 0,92 & 1,05 & 0,80 & 1,59 & 0,94 & 1,02 & 1,19 & 1,47 & 0,91 \\
\hline 5 & 1,05 & 0,95 & 0,88 & 1,07 & 1,47 & 1,11 & 0,94 & 1,06 & 0,87 & 1,77 & 0,91 & 1,00 & 1,15 & 1,45 & 0,92 \\
\hline 6 & 1,04 & 0,95 & 0,88 & 1,09 & 1,51 & 1,12 & 0,96 & 1,05 & 0,97 & 1,87 & 0,89 & 0,98 & 1,11 & 1,39 & 0,93 \\
\hline 7 & 1,04 & 0,95 & 0,88 & 1,09 & 1,51 & 1,12 & 0,96 & 1,05 & 0,97 & 1,87 & 0,89 & 0,98 & 1,11 & 1,39 & 0,93 \\
\hline 8 & 1,03 & 0,92 & 0,88 & 1,10 & 1,61 & 1,11 & 1,00 & 1,08 & 1,10 & 1,96 & 0,85 & 0,92 & 1,00 & 1,29 & 0,91 \\
\hline 9 & 1,05 & 0,91 & 0,90 & 1,08 & 1,67 & 1,09 & 1,05 & 1,12 & 1,10 & 2,02 & 0,83 & 0,90 & 0,97 & 1,24 & 0,91 \\
\hline 10 & 1,08 & 0,90 & 0,91 & 1,03 & 1,72 & 1,10 & 1,08 & 1,10 & 1,06 & 1,94 & 0,81 & 0,87 & 0,93 & 1,19 & 0,91 \\
\hline 11 & 1,11 & 0,89 & 0,92 & 0,98 & 1,79 & 1,06 & 1,09 & 1,08 & 1,05 & 1,87 & 0,80 & 0,84 & 0,90 & 1,13 & 0,89 \\
\hline 12 & 1,18 & 0,87 & 0,94 & 0,95 & 1,90 & 1,09 & 1,11 & 1,09 & 1,03 & 1,87 & 0,80 & 0,81 & 0,88 & 1,07 & 0,89 \\
\hline \multicolumn{16}{|c|}{ BVAR(p) respecto a un modelo camino aleatorio (RW) } \\
\hline \multirow{2}{*}{ Horizonte } & \multicolumn{5}{|c|}{ M2 } & \multicolumn{5}{|c|}{ M3 } & \multicolumn{5}{|c|}{ M4 } \\
\hline & IMACEC & IPC & IPCX1 & TPM & TCR & IMACEC & IPC & IPCX1 & TPM & TCR & IMACEC & IPC & IPCX1 & TPM & TCR \\
\hline 1 & 0,71 & 0,40 & 0,38 & 0,34 & 0,70 & 0,82 & 0,36 & 0,36 & 0,40 & 0,70 & 0,67 & 0,48 & 0,44 & 0,54 & 0,64 \\
\hline 2 & 0,83 & 0,54 & 0,45 & 0,49 & 1,02 & 0,87 & 0,52 & 0,45 & 0,51 & 1,03 & 0,74 & 0,61 & 0,53 & 0,72 & 0,80 \\
\hline 3 & 0,82 & 0,59 & 0,44 & 0,58 & 1,30 & 0,85 & 0,59 & 0,48 & 0,52 & 1,40 & 0,71 & 0,66 & 0,56 & 0,82 & 0,90 \\
\hline 4 & 0,83 & 0,64 & 0,45 & 0,64 & 1,44 & 0,86 & 0,62 & 0,52 & 0,48 & 1,64 & 0,73 & 0,69 & 0,58 & 0,89 & 0,94 \\
\hline 5 & 0,83 & 0,67 & 0,47 & 0,69 & 1,54 & 0,88 & 0,66 & 0,56 & 0,56 & 1,86 & 0,73 & 0,70 & 0,61 & 0,93 & 0,96 \\
\hline 6 & 0,98 & 0,77 & 0,56 & 0,83 & 1,74 & 1,06 & 0,77 & 0,67 & 0,75 & 2,15 & 0,83 & 0,80 & 0,71 & 1,07 & 1,06 \\
\hline 7 & 0,79 & 0,62 & 0,43 & 0,70 & 1,54 & 0,86 & 0,62 & 0,51 & 0,63 & 1,91 & 0,68 & 0,64 & 0,54 & 0,90 & 0,94 \\
\hline 8 & 0,90 & 0,70 & 0,55 & 0,88 & 1,89 & 0,96 & 0,76 & 0,67 & 0,88 & 2,30 & 0,74 & 0,70 & 0,62 & 1,03 & 1,07 \\
\hline 9 & 0,91 & 0,70 & 0,58 & 0,91 & 2,04 & 0,95 & 0,80 & 0,71 & 0,93 & 2,47 & 0,72 & 0,68 & 0,62 & 1,05 & 1,11 \\
\hline 10 & 0,95 & 0,70 & 0,61 & 0,92 & 2,11 & 0,96 & 0,84 & 0,73 & 0,94 & 2,38 & 0,71 & 0,67 & 0,62 & 1,06 & 1,11 \\
\hline 11 & 0,96 & 0,69 & 0,64 & 0,93 & 2,20 & 0,91 & 0,85 & 0,75 & 1,00 & 2,30 & 0,69 & 0,66 & 0,63 & 1,08 & 1,09 \\
\hline 12 & 0,97 & 0,69 & 0,66 & 0,84 & 2,00 & 0,89 & 0,88 & 0,77 & 0,92 & 1,97 & 0,66 & 0,64 & 0,62 & 0,95 & 0,93 \\
\hline \multicolumn{16}{|c|}{ BVAR(p) respecto a un modelo ARIMA (Akaike) } \\
\hline Horizonto & & & M2 & & & & & M3 & & & & & M4 & & \\
\hline Horizonte & IMACEC & IPC & IPCX1 & TPM & TCR & IMACEC & IPC & IPCX1 & TPM & TCR & IMACEC & IPC & IPCX1 & TPM & TCR \\
\hline 1 & 0,77 & 0,50 & 0,56 & 0,40 & 0,70 & 0,88 & 0,46 & 0,53 & 0,46 & 0,70 & 0,72 & 0,60 & 0,64 & 0,62 & 0,63 \\
\hline 2 & 0,92 & 0,69 & 0,72 & 0,54 & 0,99 & 0,97 & 0,66 & 0,72 & 0,56 & 1,00 & 0,83 & 0,78 & 0,85 & 0,79 & 0,77 \\
\hline 3 & 0,93 & 0,77 & 0,74 & 0,62 & 1,25 & 0,97 & 0,76 & 0,80 & 0,55 & 1,35 & 0,81 & 0,85 & 0,93 & 0,88 & 0,87 \\
\hline 4 & 0,96 & 0,83 & 0,74 & 0,67 & 1,39 & 1,00 & 0,81 & 0,86 & 0,51 & 1,58 & 0,84 & 0,90 & 0,97 & 0,94 & 0,90 \\
\hline 5 & 0,99 & 0,89 & 0,77 & 0,72 & 1,48 & 1,05 & 0,88 & 0,93 & 0,58 & 1,78 & 0,87 & 0,94 & 1,01 & 0,97 & 0,92 \\
\hline 6 & 1,13 & 1,01 & 0,94 & 0,87 & 1,65 & 1,22 & 1,02 & 1,12 & 0,78 & 2,04 & 0,96 & 1,05 & 1,18 & 1,11 & 1,01 \\
\hline 7 & 0,99 & 0,88 & 0,71 & 0,73 & 1,43 & 1,07 & 0,88 & 0,84 & 0,65 & 1,78 & 0,85 & 0,91 & 0,89 & 0,93 & 0,88 \\
\hline 8 & 1,16 & 1,03 & 0,90 & 0,91 & 1,73 & 1,24 & 1,12 & 1,11 & 0,91 & 2,10 & 0,95 & 1,02 & 1,03 & 1,06 & 0,98 \\
\hline 9 & 1,19 & 1,07 & 0,97 & 0,94 & 1,86 & 1,25 & 1,24 & 1,20 & 0,96 & 2,24 & 0,95 & 1,05 & 1,05 & 1,08 & 1,01 \\
\hline 10 & 1,28 & 1,11 & 1,03 & 0,95 & 1,90 & 1,31 & 1,33 & 1,24 & 0,97 & 2,14 & 0,96 & 1,07 & 1,05 & 1,10 & 1,00 \\
\hline 11 & 1,34 & 1,13 & 1,07 & 0,95 & 1,97 & 1,27 & 1,39 & 1,26 & 1,02 & 2,05 & 0,96 & 1,07 & 1,05 & 1,10 & 0,98 \\
\hline 12 & 1,32 & 1,09 & 1,12 & 0,86 & 1,79 & 1,21 & 1,38 & 1,29 & 0,94 & 1,76 & 0,89 & 1,01 & 1,05 & 0,98 & 0,83 \\
\hline $\operatorname{BVAR}(\mathrm{p})$ & ecto a & d & $\operatorname{delo~} \mathrm{Al}$ & IMA ( & (BIC) & & & & & & & & & & \\
\hline Horiz & & & M2 & & & & & M3 & & & & & M4 & & \\
\hline Horizo & IMACEC & IPC & IPCX1 & TPM & TCR & IMACEC & IPC & IPCX1 & TPM & TCR & IMACEC & IPC & IPCX1 & TPM & TCR \\
\hline 1 & 0,77 & 0,52 & 0,60 & 0,40 & 0,68 & 0,88 & 0,47 & 0,56 & 0,46 & 0,68 & 0,72 & 0,62 & 0,69 & 0,62 & 0,62 \\
\hline 2 & 0,92 & 0,70 & 0,75 & 0,54 & 0,98 & 0,97 & 0,68 & 0,75 & 0,56 & 0,99 & 0,83 & 0,79 & 0,88 & 0,79 & 0,76 \\
\hline 3 & 0,93 & 0,79 & 0,76 & 0,62 & 1,25 & 0,97 & 0,78 & 0,83 & 0,55 & 1,35 & 0,81 & 0,87 & 0,96 & 0,88 & 0,87 \\
\hline 4 & 0,96 & 0,85 & 0,75 & 0,67 & 1,38 & 1,00 & 0,82 & 0,88 & 0,51 & 1,58 & 0,84 & 0,91 & 0,99 & 0,94 & 0,90 \\
\hline 5 & 0,99 & 0,90 & 0,77 & 0,72 & 1,46 & 1,05 & 0,89 & 0,92 & 0,58 & 1,77 & 0,87 & 0,95 & 1,00 & 0,97 & 0,91 \\
\hline 6 & 1,13 & 1,03 & 0,89 & 0,87 & 1,63 & 1,22 & 1,04 & 1,06 & 0,78 & 2,02 & 0,96 & 1,07 & 1,12 & 1,11 & 1,00 \\
\hline 7 & 0,99 & 0,88 & 0,69 & 0,73 & 1,46 & 1,07 & 0,89 & 0,83 & 0,65 & 1,81 & 0,85 & 0,91 & 0,87 & 0,93 & 0,89 \\
\hline 8 & 1,16 & 1,04 & 0,89 & 0,91 & 1,81 & 1,24 & 1,13 & 1,09 & 0,91 & 2,20 & 0,95 & 1,04 & 1,01 & 1,06 & 1,03 \\
\hline 9 & 1,19 & 1,09 & 0,96 & 0,94 & 1,94 & 1,25 & 1,25 & 1,18 & 0,96 & 2,34 & 0,95 & 1,06 & 1,03 & 1,08 & 1,06 \\
\hline 10 & 1,28 & 1,13 & 1,01 & 0,95 & 1,98 & 1,31 & 1,35 & 1,22 & 0,97 & 2,23 & 0,96 & 1,08 & 1,03 & 1,10 & 1,04 \\
\hline 11 & 1,34 & 1,16 & 1,05 & 0,95 & 2,03 & 1,27 & 1,42 & 1,23 & 1,02 & 2,11 & 0,96 & 1,09 & 1,03 & 1,10 & 1,00 \\
\hline 12 & 1,32 & 1,10 & 1,09 & 0,86 & 1,86 & 1,21 & 1,40 & 1,26 & 0,94 & 1,84 & 0,89 & 1,02 & 1,02 & 0,98 & 0,87 \\
\hline
\end{tabular}




\begin{tabular}{|c|c|c|c|c|c|c|c|c|c|c|c|c|c|c|}
\hline \multicolumn{15}{|c|}{ BVAR(p) respecto a un modelo VAR simple } \\
\hline \multicolumn{4}{|c|}{ M5 } & \multicolumn{4}{|c|}{ M6 } & \multicolumn{4}{|c|}{ M7 } & \multicolumn{3}{|c|}{ M8 } \\
\hline $\mathrm{EC}$ & IPC & IPCX1 & TPM TCR & IMACEC & IPC & IPCX1 & TPM TCR & IMACEC & IPC & IPCX1 & TPM TCR & IMACEC & IPC IPCX1 & TPM TCR \\
\hline 0,96 & 1,12 & 1,14 & $1,560,95$ & 0,96 & 1,12 & 1,16 & 0,95 & 0,96 & 1,14 & 1,19 & $1,550,95$ & 0,97 & $1,15 \quad 1,21$ & ,55 0,95 \\
\hline 0,95 & 1,04 & 1,18 & $\begin{array}{ll}48 & 0,92\end{array}$ & 0,95 & 1,05 & 1,20 & 0,92 & & 1,07 & 1,25 & $\begin{array}{ll}48 & 0,92\end{array}$ & 0,96 & $1,09 \quad 1,29$ & ,47 0,92 \\
\hline 0,94 & 1,05 & 1,22 & $1,470,90$ & 0,94 & 1,06 & 1,26 & $1,460,90$ & 0,95 & 1,09 & 1,31 & $1,460,89$ & 0,96 & $1,11 \quad 1,36$ & $1,460,89$ \\
\hline 0,94 & 1,03 & 1,20 & $1,47 \quad 0,91$ & 0,94 & 1,05 & 1,24 & $1,460,91$ & 0,95 & 1,08 & 1,30 & $1,460,91$ & 0,97 & $1,10 \quad 1,35$ & $1,460,90$ \\
\hline 0,92 & 1,01 & 1,16 & $1,44 \quad 0,91$ & 0,92 & 1,03 & 1,20 & 0,91 & 0,93 & 1,06 & 1,26 & $1,430,91$ & & $1,09 \quad 1,31$ & 30,91 \\
\hline 0,89 & 0,99 & 1,12 & $\begin{array}{lll}1,39 & 0,93\end{array}$ & 0,89 & 1,01 & 1,16 & $1,380,92$ & 0,90 & 1,05 & 1,23 & $1,380,92$ & 0,92 & $1,08 \quad 1,28$ & $1,380,92$ \\
\hline 0,89 & 0,99 & 1,12 & $\begin{array}{lll}1,39 & 0,93\end{array}$ & 0,89 & 1,01 & 1,16 & $1,380,92$ & 0,90 & 1,05 & 1,23 & $1,380,92$ & 0,92 & $1,08 \quad 1,28$ & $1,380,92$ \\
\hline 0,85 & 0,93 & 1,02 & $1,280,91$ & 0,85 & 0,96 & 1,06 & 0,91 & & 1,00 & 1,13 & $1,270,90$ & & $1,04 \quad 1,18$ & 0,90 \\
\hline 0,83 & 0,91 & 0,99 & $1,230,91$ & 0,83 & 0,94 & 1,03 & $1,230,90$ & 0,84 & 0,99 & 1,11 & $1,220,90$ & 0,86 & $1,03 \quad 1,16$ & $1,220,89$ \\
\hline 0,81 & 0,88 & 0,95 & $1,190,90$ & 0,81 & 0,91 & 1,00 & $1,180,90$ & 0,82 & 0,97 & 1,07 & $1,170,89$ & 0,84 & $1,01 \quad 1,13$ & $1,160,89$ \\
\hline 0,79 & 0,86 & 0,92 & 0,89 & 0,79 & 0,89 & 0,97 & & & 0,95 & 1,04 & & & $0,99 \quad 1,10$ & 0,87 \\
\hline 0,80 & 0,83 & 0,91 & $1,060,88$ & 0,80 & 0,86 & 0,95 & 1,0 & 0,8 & 0,92 & 1,03 & 1, & 0,83 & $0,97 \quad 1,09$ & 0,87 \\
\hline \multicolumn{15}{|c|}{ BVAR(p) respecto a un modelo camino aleatorio (RW) } \\
\hline \multicolumn{4}{|c|}{ M5 } & \multicolumn{4}{|c|}{ M6 } & \multicolumn{4}{|c|}{ M7 } & \multicolumn{3}{|c|}{ M8 } \\
\hline IACEC & IPC & IPCX & $\mathrm{R}$ & IMACEC & IP & IPC) & $\mathrm{CR}$ & IM & IPC & IPC & $\mathrm{CR}$ & IMACEC & IPC IPCX & TCR \\
\hline 0,67 & 0,48 & 44 &, 64 & 0,67 & 0,48 & 0,45 & 0,63 & 67 & 0,49 & 0,46 & 63 & 67 & $0,50 \quad 0,47$ & 0,63 \\
\hline 0,74 & 0,61 & 0,53 & 0,7 & 0,75 & 0,62 & 0,55 & 0 & & 0,63 & 0,57 & $0,720,79$ & 76 & $0,64 \quad 0,58$ & $0,720,79$ \\
\hline 0,71 & 0,66 & 0,57 & $0,82 \quad 0,90$ & 0,71 & 0,67 & 0,58 & $0,820,90$ & 72 & 0,69 & 0,61 & $0,820,90$ & 0,73 & $0,70 \quad 0,63$ & $0,820,90$ \\
\hline 0,73 & 0,69 & 0,59 & 0,88 & 0,73 & 0,70 & 0,61 & 0,94 & & 0,72 & 0,64 & 0,93 & & $0,74 \quad 0,66$ & 0,93 \\
\hline 0,73 & 0,71 & 0,61 & $0,930,96$ & 0,73 & 0,72 & 0,63 & $0,930,96$ & 0 & 0,75 & 0,67 & $0,920,96$ & 0,75 & $\begin{array}{lll}0,77 & 0,69\end{array}$ & $0,920,95$ \\
\hline 0,83 & 0,80 & 0,72 & $1,061,06$ & 0,84 & 0,82 & 0,74 & $1,061,06$ & 0,85 & 0,85 & 0,79 & $1,061,05$ & & $0,88 \quad 0,82$ & $1,05 \quad 1,05$ \\
\hline 0,68 & 0,64 & 0,55 & 0,90 & 0,68 & 0,66 & 0,57 & 0,8 & & 0,68 & 0,60 & 0,94 & & $0,70 \quad 0,63$ & 0,93 \\
\hline 0,74 & 0,71 & 0,63 & $1,021,07$ & 0,74 & 0,72 & 0,66 & $1,021,07$ & 0 & 0,76 & 0,70 & $1,01 \quad 1,06$ & 0,77 & $0,79 \quad 0,74$ & $1,011,06$ \\
\hline 0,72 & 0,69 & 0,63 & $1,041,11$ & 0,72 & 0,72 & 0,66 & $1,04 \quad 1,11$ & & 0,75 & 0,71 & $1,03 \quad 1,10$ & 0,74 & $0,78 \quad 0,74$ & $1,03 \quad 1,09$ \\
\hline 0,71 & 0,68 & 0,64 & $1,061,11$ & 0,71 & 0,71 & 0,67 & 1,0 & & 0,75 & 0,72 & $+1,09$ & & $0,78 \quad 0,75$ & $1,04 \quad 1,09$ \\
\hline 0,69 & 0,67 & 0,64 & $1,07 \quad 1,09$ & 0,69 & 0,69 & 0,67 & 1,0 & & 0,74 & 0,72 & 1,07 & 0,71 & $0,77 \quad 0,76$ & $1,05 \quad 1,07$ \\
\hline 0,66 & 0,65 & 0,64 & $0,950,93$ & 0,66 & 0,68 & 0,67 & $0,940,92$ & 0,67 & 0,73 & 0,72 & $0,930,91$ & 0,69 & $0,76 \quad 0,76$ & $0,920,91$ \\
\hline \multicolumn{15}{|c|}{ BVAR(p) respecto a un modelo ARIMA (Akaike) } \\
\hline \multicolumn{4}{|c|}{ M5 } & & & M6 & & & & M7 & & & M8 & \\
\hline $\mathrm{MA}$ & IPC & $\mathrm{IP}$ & $\mathrm{R}$ & IN & IPC & IPC & $\mathrm{CR}$ & $\mathrm{IM}$ & ITC & IPCX & TCR & IMACEC & IPC IPCX & PM TCR \\
\hline 0,72 & 0,60 & 0,65 & 63 & 72 & 0,61 & 0,66 & 63 & 072 & 0,62 & 0,68 & 0, &, 73 & $0,630,69$ & 0,63 \\
\hline & 0,78 & 0,85 & & & 0,7 & 0,87 & & & 0,80 & 0,91 & 0 & & $0,82 \quad 0,93$ & 077 \\
\hline 0,81 & 0,85 & 0,94 & 0 , & 31 & 0,86 & 0,97 & 87 & 82 & 0,89 & 1,01 & 0,8 & 0,83 & $0,90 \quad 1,05$ & 0,86 \\
\hline 0,84 & 0,90 & 0,98 & 0 , & & 0,92 & 1,01 & $0,930,90$ & & 0,94 & 1,06 & 0,9 & 0,87 & $0,97 \quad 1,10$ & 0,90 \\
\hline & 0,95 & 1,02 & & & 0,97 & 1,05 & & & 1,00 & 1,11 & $0,960,92$ & & $1,02 \quad 1,15$ & 6090 \\
\hline 0,96 & 1,06 & 1,20 & 1,1 & & 1,08 & 1,24 & & & 1,12 & 1,31 & & 0 & $1,15 \quad 1,37$ & $1,101,00$ \\
\hline 0,85 & 0,92 & 0,91 & $0,930,88$ & 0,85 & 0,94 & 0,94 & $\begin{array}{lll}0,93 & 0,87\end{array}$ & 0,86 & 0,97 & 0,99 & $\begin{array}{lll}0,92 & 0,87\end{array}$ & 0,88 & $1,00 \quad 1,03$ & $\begin{array}{lll}0,92 & 0,87\end{array}$ \\
\hline & 1,04 & 105 & & & 1,07 & 1,09 & & & 1,12 & 116 & 0,97 & & $1,16 \quad 1,21$ & 4097 \\
\hline & & 1,07 & & & 1,10 & 1,12 & & & 1,16 & 13 & 1, & & $1,20 \quad 1,26$ & 0,99 \\
\hline 0,96 & 1,08 & 1,08 & $1,091,00$ & 0,96 & 1,12 & 1,13 & $1,080,99$ & 0 & 1,19 & 1,21 & $1,080,98$ & 1,00 & $1,24 \quad 1,27$ & $1,070,98$ \\
\hline & 1,09 & 1,08 & & & 1,13 & 1,13 & & & 1,20 & 122 & & & $1,26 \quad 1,28$ & $1,070,96$ \\
\hline 0,89 & 1,03 & 1,07 & 0,97 & 0,89 & 1,07 & 1,13 & & 0,91 & 1,15 & 1,22 & 0,9 & 0,93 & $1,21 \quad 1,29$ & 0,81 \\
\hline $\mathrm{VAI}$ & $n$ & to & & $2 \mathrm{I}$ & & & & & & & & & & \\
\hline & & M5 & & & & M6 & & & & M7 & & & M8 & \\
\hline MACEC & IPC & IPCX1 & P TCR & IMACEC & IPC & IPCX & M TCR & IMACEC & IPC & IPCX & TCR & IMACEC & IPC IPCX & TPM TCR \\
\hline 0,72 & 0,62 & 60 & 60 & 0 77 & 62 & 07 & & & 0,63 & 0,7 & & 073 & $0,64 \quad 0,74$ & 06 \\
\hline & 0,8 & & & & & & & & & 00 & & 0,84 & $0,83 \quad 0,97$ & \\
\hline 0,81 & 0,87 & 0,97 & $\begin{array}{lll}0,88 & 0,87\end{array}$ & 0,81 & 0,88 & 1,00 & $\begin{array}{lll}0,88 & 0,87\end{array}$ & 0,82 & 0,91 & 1,04 & $0,870,87$ & 0,83 & $0,93 \quad 1,08$ & $0,870,87$ \\
\hline & 0,92 & 1,00 & & & 0,93 & 1,03 & & & 0,96 & 10 & & 0,87 & $0,98 \quad 1,12$ & \\
\hline & 0,96 & 1,01 & 0,9 & & 0,98 & 1,04 & & & 1,01 & 1,10 & 0,960 & 0,90 & $1,03 \quad 1,14$ & $0,960,90$ \\
\hline 0,96 & 1,08 & 1,14 & $1,11 \quad 1,00$ & 0,97 & 1,10 & 1,18 & $1,11 \quad 1,00$ & 0,98 & 1,15 & 1,24 & $1,100,99$ & 1,00 & $1,18 \quad 1,30$ & $\begin{array}{ll}1,10 & 0,99\end{array}$ \\
\hline & 0,92 & 0,89 & & & 0,94 & 0,92 & & & 0,98 & 0,97 & & 0,88 & $1,01 \quad 1,01$ & \\
\hline & 1,05 & 1,03 & 1,0 & & 1,08 & 1,07 & 1,051 & 0 , & 1,13 & 1,1 & 1,0 & 0,98 & $1,17 \quad 1,19$ & $1,04 \quad 1,01$ \\
\hline 0,94 & 1,08 & 1,05 & $1,08 \quad 1,06$ & 0,95 & 1,11 & 1,10 & $1,07 \quad 1,05$ & 0,96 & 1,17 & 1,18 & $1,07 \quad 1,04$ & 0,98 & $1,22 \quad 1,24$ & $1,061,04$ \\
\hline & 1,10 & 1,06 & 1,091, & 0,96 & 1,14 & 1,11 & $1,081,03$ & 0,98 & 1,21 & 1,19 & $1,08 \quad 1,02$ & 1,00 & $1,26 \quad 1,25$ & $1,07 \quad 1,02$ \\
\hline & 1,11 & 1,06 & 1,1 & 0,9 & 1,16 & 1,11 & $1,091,00$ & 0 , & 1,23 & 1,19 & 1,0 & 1,00 & $1,29 \quad 1,26$ & $1,070,98$ \\
\hline 0,89 & 1,04 & 1,05 & $0,970,87$ & 0,89 & 1,09 & 1,10 & $0,960,86$ & 0,91 & 1,17 & 1,19 & $0,950,85$ & 0,93 & $1,22 \quad 1,26$ & $0,940,85$ \\
\hline
\end{tabular}




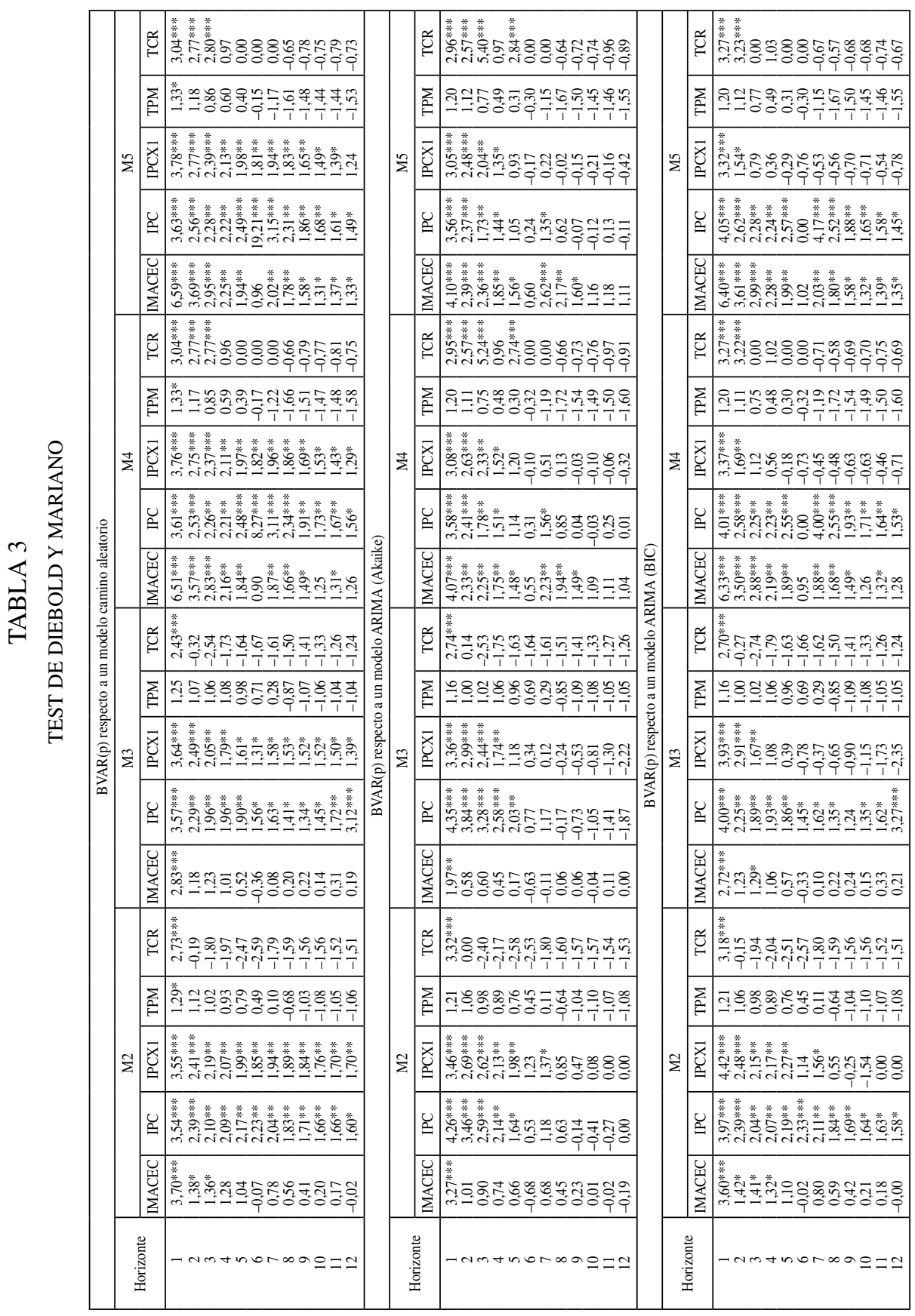




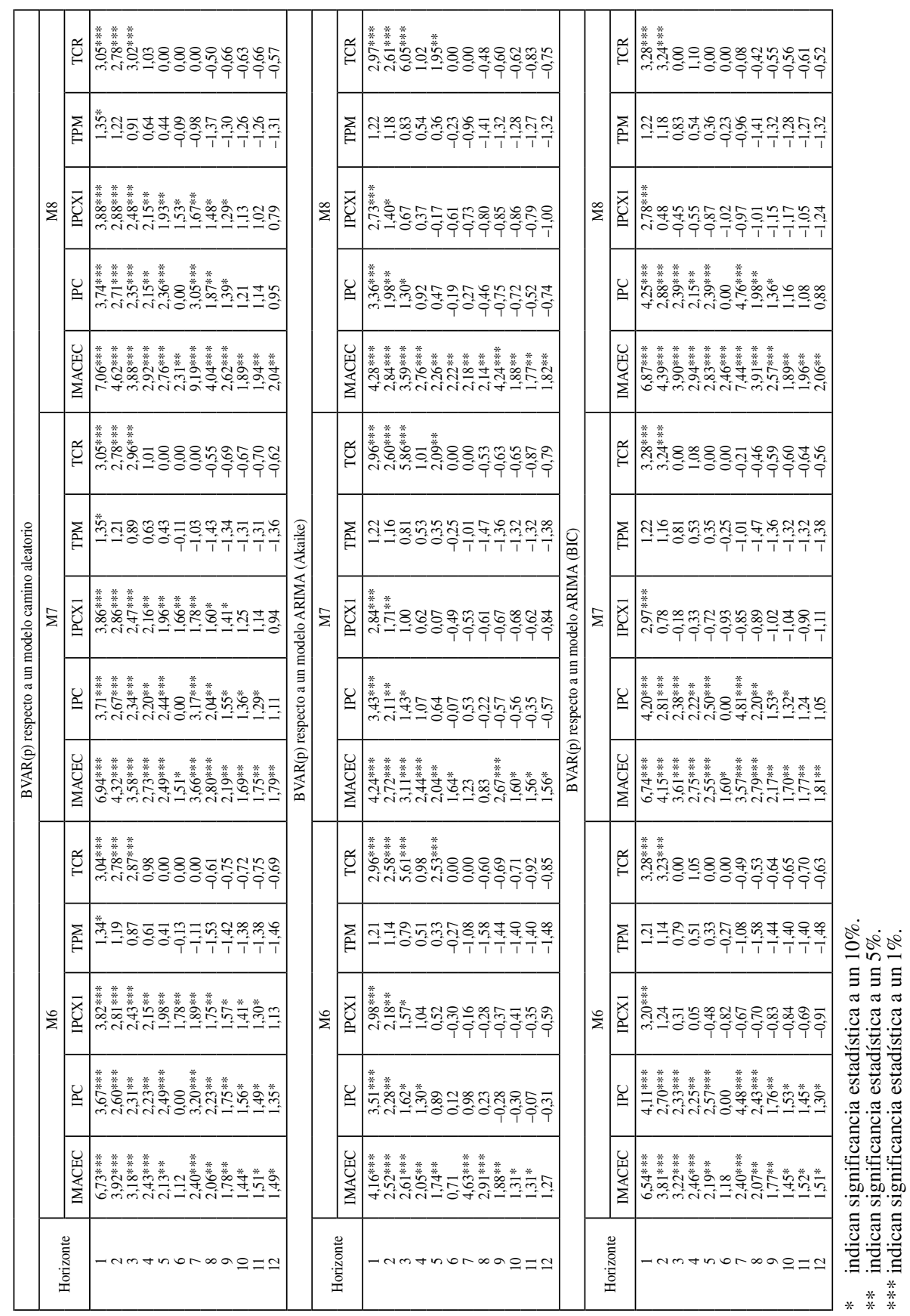


Boivin y Eliasz (2005) se divide el set de datos en dos grupos, uno de movimiento rápido (fast moving) y otro de movimiento lento (low moving).

La identificación de los shocks se realiza de la siguiente manera: ordenamos las variables $Y_{t}=\left(X_{t}, r_{t}, Z_{t}\right)^{\prime}$, donde $X_{t}$ contiene las $n_{1}$ variables de movimiento lento, $r_{t}$ es el instrumento de política monetaria (en el caso posterior es el índice bursátil y la prima por riesgo) y $Z_{t}$ contiene las $n_{2}$ variables de movimiento rápido, se asume que el shock $\left(r_{t}\right)$ es ortogonal a todos los otros shocks de la economía. Sea $B=C D^{1 / 2}$ una matriz baja diagonal Cholesky de covarianzas de los residuos del VAR de forma reducida, esto es $C D C^{\prime}=E\left[u_{t} u_{t}^{\prime}\right]=\Psi$ y $D=\operatorname{diag}(\Psi)$. Sea $e_{t}$ la transformación lineal de los residuos del VAR, $e_{t}=\left(e_{1 t}, \ldots, e_{n t}\right)^{\prime}=C^{-1} u_{t}$. El shock de política monetaria es la fila de ET $e_{t}$ correspondiente a la posición $r_{t}$, este es $e_{n_{1}+1, t}$.

El VAR estructural es igual a:

$$
A_{0} Y_{t}=v+A_{1} Y_{t-1}+\ldots+A_{p} Y_{t-p}+e_{t}, e_{t} \sim N(0, D)
$$

donde $v=C^{-1} c, A_{0}=C^{-1}$ y $A_{j}=C^{-1} A_{j}, j=1, \ldots, p$. Los impulsos respuestas consisten en aumentar en $100 \mathrm{pb}$ la tasa de política monetaria y posteriormente en otro ejercicio aumentar en $10 \%$ el índice de la bolsa de comercio (IGPA). Dado que el VAR está justamente identificado, los impulsos respuesta son computados siguiendo a Canova (1991) y a Gordon y Leeper (1994), generando muestras de la posterior de $\left(A_{1}, \ldots, A_{p}, \Psi\right)$. Para cada muestra de $\Psi$ se calculan $B$ y $C$, siendo posible así obtener $A_{j}, j=0, \ldots, p$.

\subsection{Shock monetario}

En el shock monetario consideramos un aumento de 100 pb en la tasa de política monetaria (TPM) (Gráfico 1a). En este se observa una respuesta fuerte y significativa para el caso de la actividad económica, encontrándose en línea con los resultados de Parrado (2001), y no son muy distintos a los obtenidos por Medina y Soto (2007) en el modelo de equilibrio general para la economía chilena. Para el caso de la inflación (medida por el IPC) esta cae al igual que el IMACEC, no encontrándose ningún puzzle de precios típicamente hallado en el caso de los impulsos respuesta de la inflación, a excepción en el IPCX1 en el cual sí se observa el price puzzle que aparece en algunos casos en los VAR's. También se encuentran resultados muy intuitivos, como es el caso del agregado monetario M0 que se reduce inmediatamente seguido al shock, en tanto el TCR y el índice de bolsa (IGPA) retroceden con algo más de rezago.

Dentro de las ventajas del gran VAR bayesiano está la capacidad de poder extender el análisis de la transmisión de los shocks más allá de lo típicamente observado dentro de la literatura de los VAR's. Es así que el traspaso de los cambios en la tasa de política monetaria es cercano a uno en las tasa nominales en todos los plazos (Gráfico 1b). Al tomar en cuenta las tasas reales vemos que la transmisión es mayor en los plazos más cortos que en los plazos más largos. El stock de las colocaciones promedio del sistema financiero retrocede ante al shock y al observar la serie por tipo de agente vemos que las colocaciones de consumo caen con mayor fuerza, en tanto las de vivienda caen 


\section{GRAFICO 1A}

IMPULSO RESPUESTA A UN SHOCK DE POLITICA MONETARIA (TPM). EFECTO EN VARIABLES MACROECONOMICAS
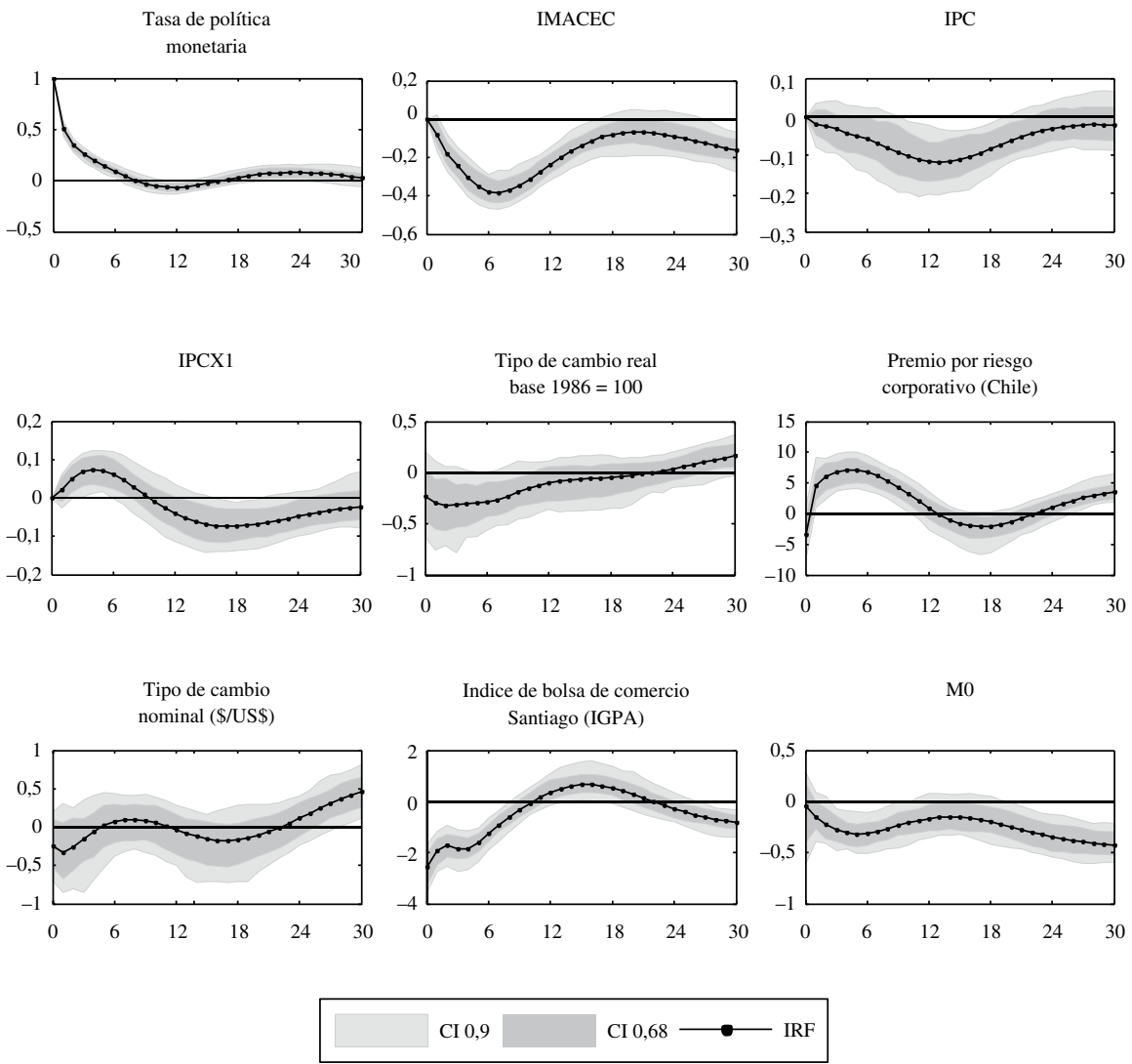

con algo más de retraso; por último, las comerciales inicialmente aumentan pero con algo de rezago se contraen en respuesta al shock de política monetaria.

Otro de los resultados poco convencionales observados dentro de la literatura es la respuesta de las exportaciones e importaciones (Gráfico 1c). En este caso vemos que ambas reaccionan a la baja, aunque las importaciones retroceden con mayor fuerza que las exportaciones, dando a entender una mejora en las exportaciones netas. Observando los datos desagregados nos encontramos con el puzzle en la respuesta de las exportaciones agrícolas, que aumentan después del shock de política monetaria.

En general podemos observar que las exportaciones no reaccionan de manera significativa al shock de política monetaria, siendo quizás la industria el único caso en el cual se pueda decir que este reacciona significativamente al shock, en tanto las 


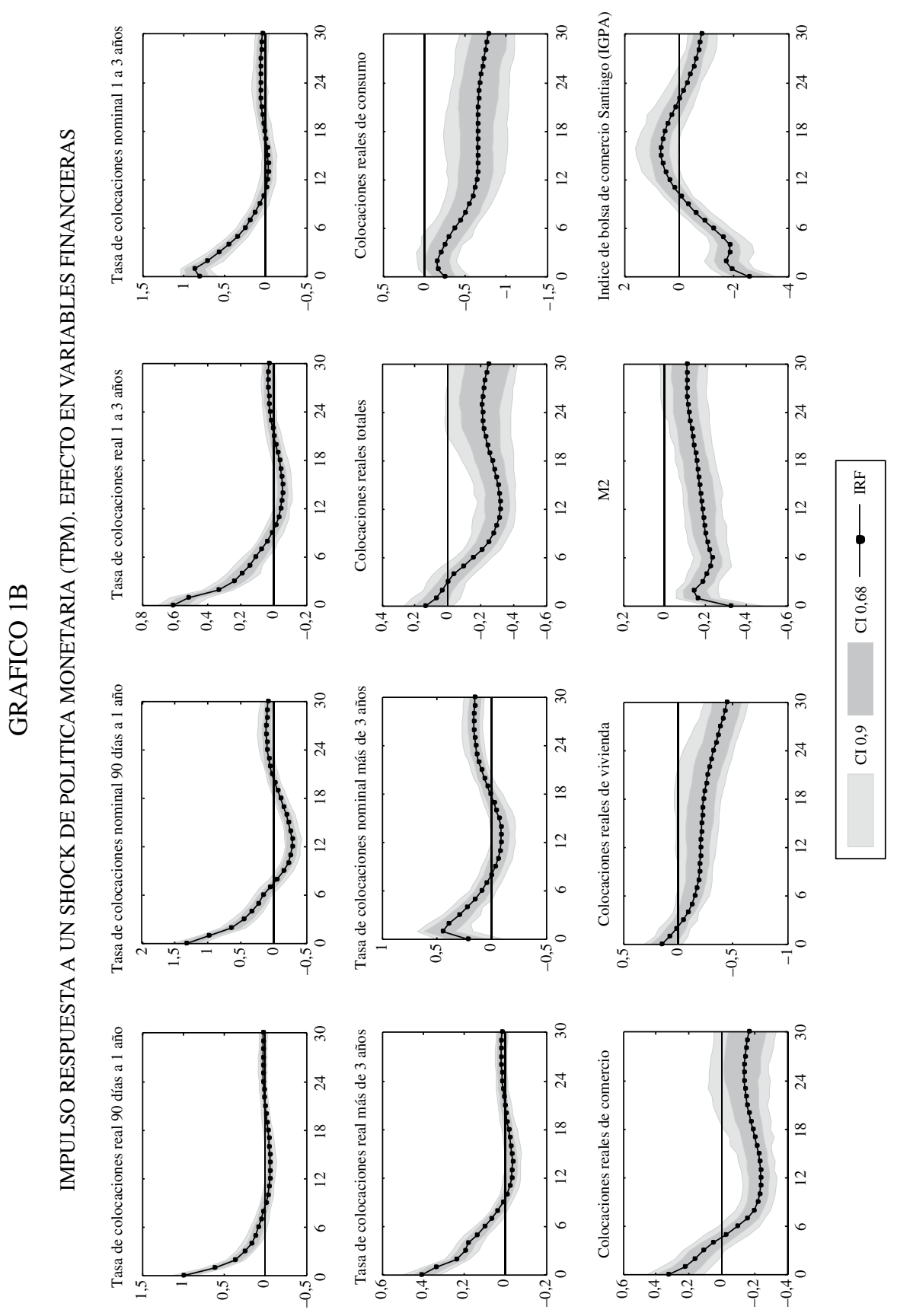




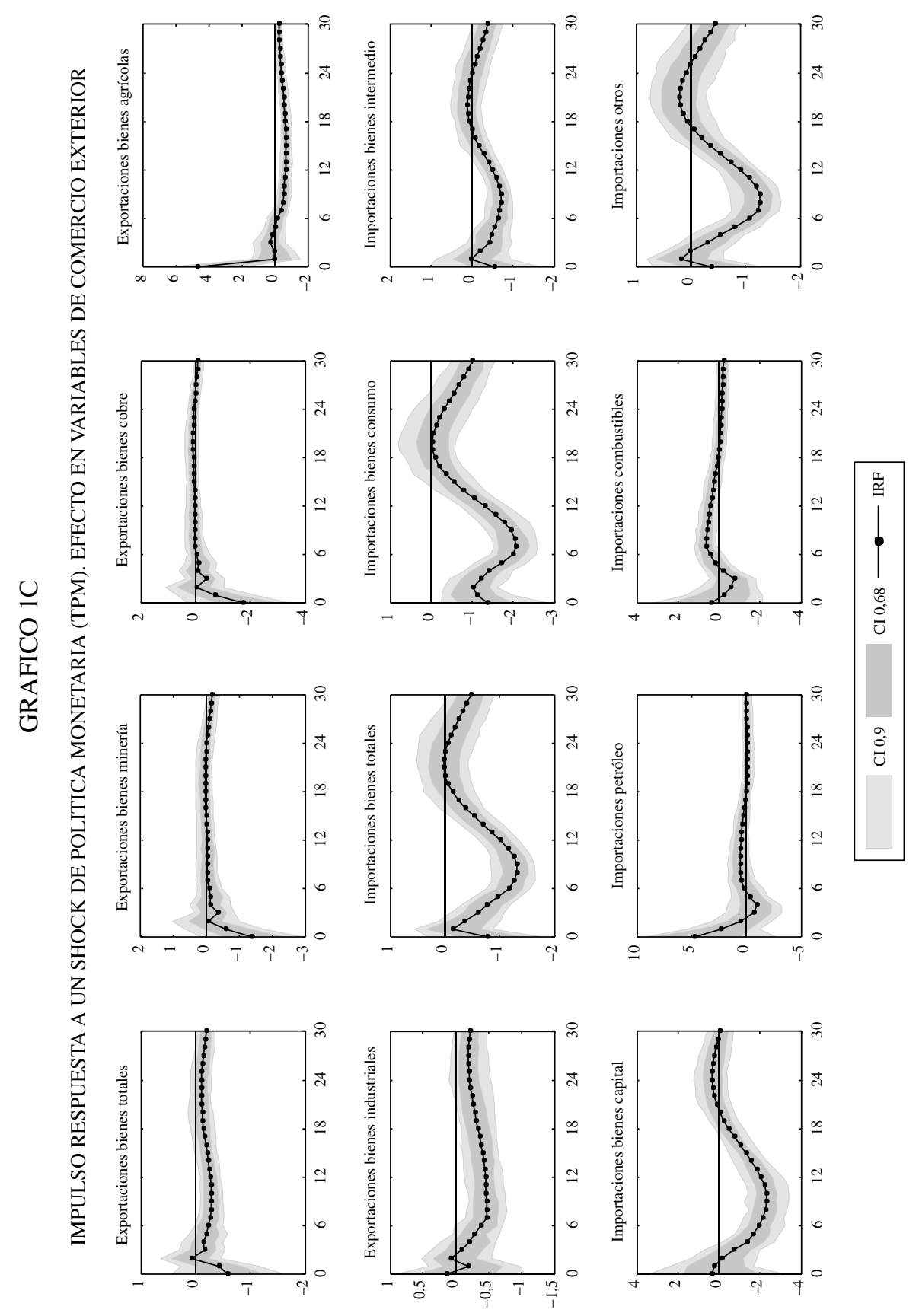


importaciones tienen una respuesta fuerte y significativa ante el shock, especialmente en las importaciones de consumo y de capital.

En el caso de la respuesta de los precios desagregados (Gráfico 1d), se puede observar el price puzzle en las medidas de precios subyacentes, específicamente en el IPCX1 y IPCX2, en el caso del IPCX este no es tan notorio. En tanto, en las medidas de inflación transable y no transable estas disminuyen ante el shock monetario, mientras también se observa el mismo resultado en los índices de bienes y servicios. En el Gráfico 1e se ve la respuesta al shock de política monetaria observando el indicador de actividad económica (IMACEC) de manera desagregada. En este caso, se observa que la respuesta del IMACEC de Resto e industria es fuerte e instantánea, al igual que el IMACEC de comercio, IVA, y derechos de importaciones. El único puzzle encontrado en la desagregación del IMACEC constituye el caso de la construcción, que inicialmente aumenta al ocurrir el shock para más tarde retroceder. La respuesta de los sectores de recursos naturales no podemos afirmar con convicción que sea significativa ante el shock de política monetaria, el IMACEC de minería retrocede pero no es significativo, en tanto, los correspondientes a EGA y Agro aumentan inicialmente y luego van retrocediendo.

En el Gráfico 1f, también es factible observar la respuesta de indicadores de coyuntura. Vemos que tanto la producción y ventas industriales del INE retroceden como respuesta al shock de política monetaria, lo cual también se aprecia en las ventas de supermercado, ventas de automóviles (ANAC) y en el consumo de electricidad. En el caso de las ventas minoristas de comercio (CNC) se observa que esta disminuye como respuesta al shock, pero analizado este indicador de manera desagregada vemos que las ventas de bienes durables retroceden con mayor fuerza. Los indicadores del mercado inmobiliario nos dan cuenta de una disminución en las ventas así como también en las ofertas de viviendas nuevas, pero con las ventas se ajustan con mayor fuerza al shock, por lo que esto hace que los meses para agotar stock aumenten ante el shock de política monetaria.

\subsection{Shock bursátil}

Para el caso del otro shock, consideramos un aumento en el índice de bolsa de Santiago (IGPA). Este canal de transmisión no ha sido estimado aún de manera formal como uno de los posibles canales de transmisión de la política monetaria para Chile ${ }^{3}$, pero en este caso pretendemos dejar que los datos nos guíen en observar cual es la respuesta de la política monetaria ante un shock financiero de esta característica, así como también cómo se comportan las demás variables después de un aumento no anticipado en el índice de bolsa de Santiago (IGPA). En el Gráfico 2a se observa la respuesta de las variables típicamente consideradas en los trabajos que tratan sobre los VAR's, es así que el shock provoca un aumento en la actividad económica, el IMACEC crece aunque lentamente traspasándose en su totalidad el shock después de 6 a 9 meses, aproximadamente. Por el lado de la respuesta del IPC vemos que este

3 En el canal bursátil por medio de un modelo estructural es analizado por Christiano et al. (2010) y por Milani (2011). 


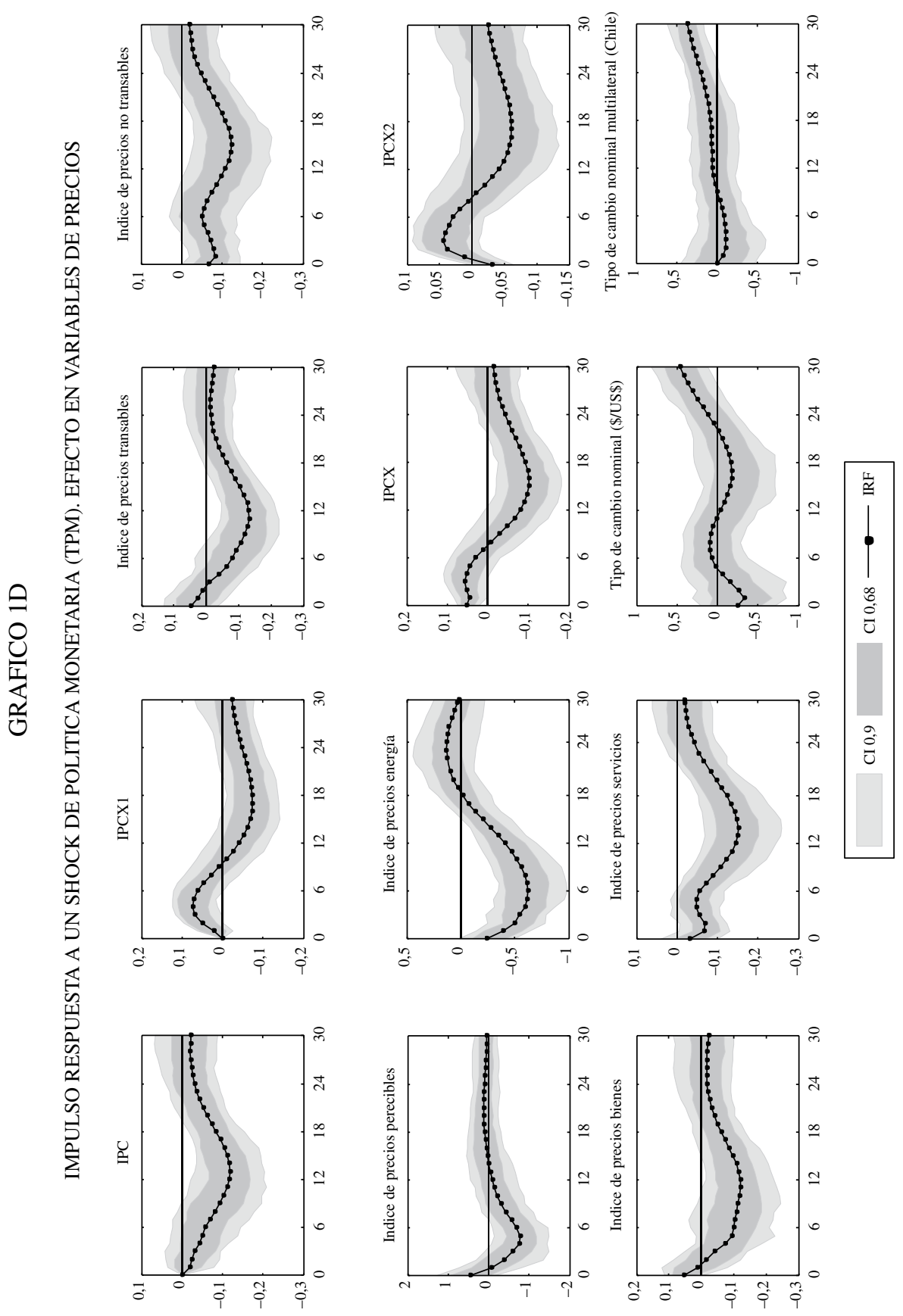




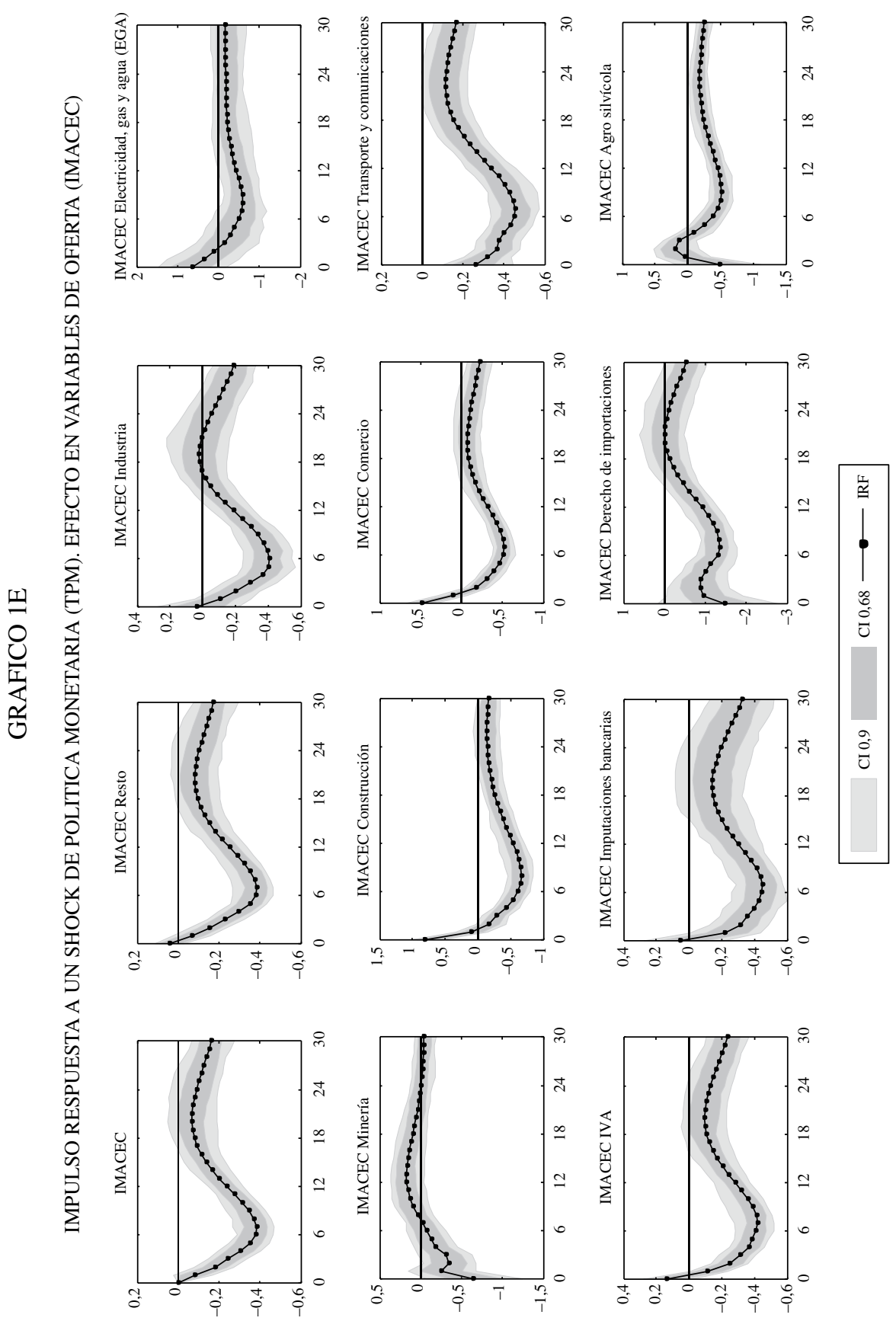




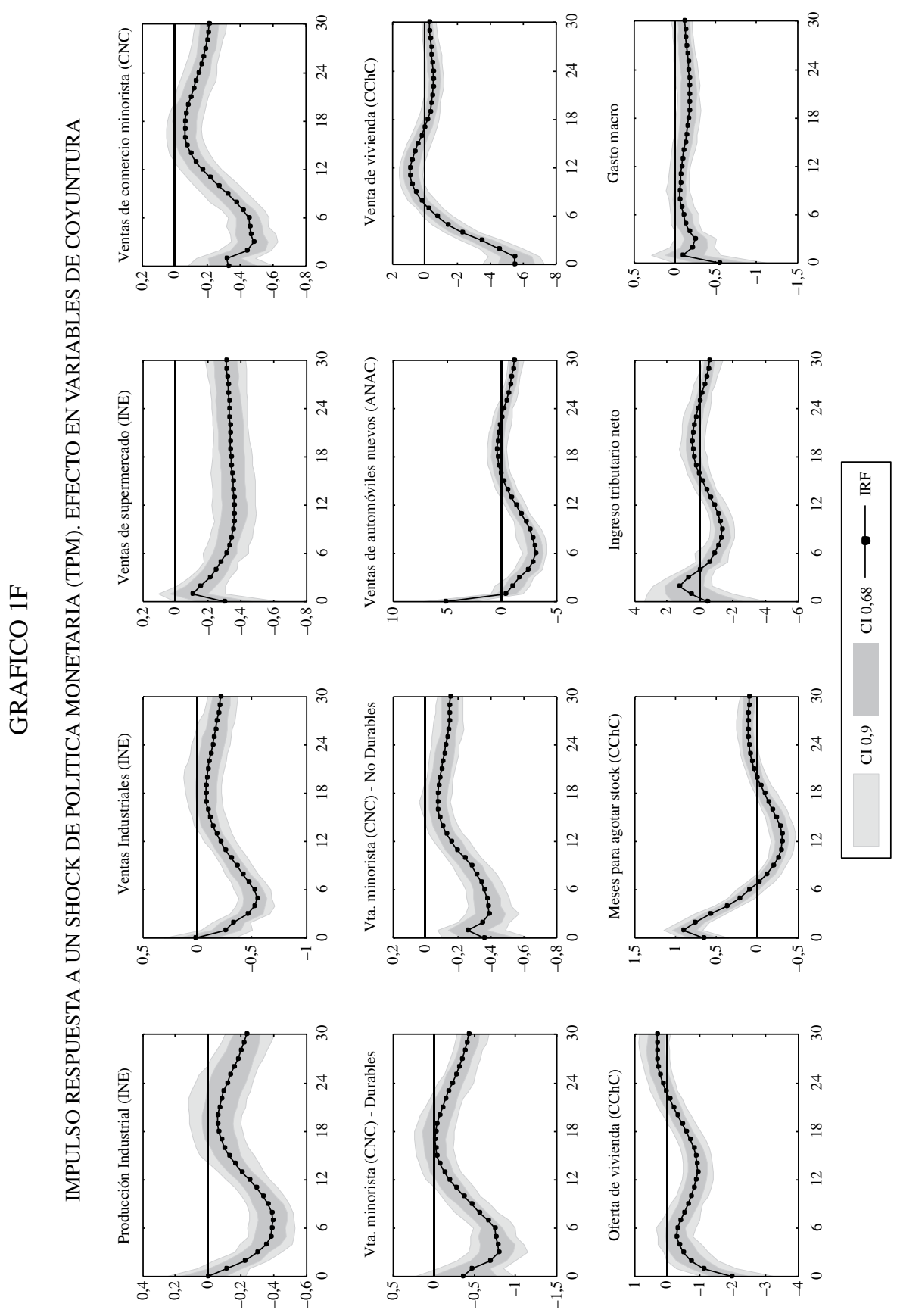




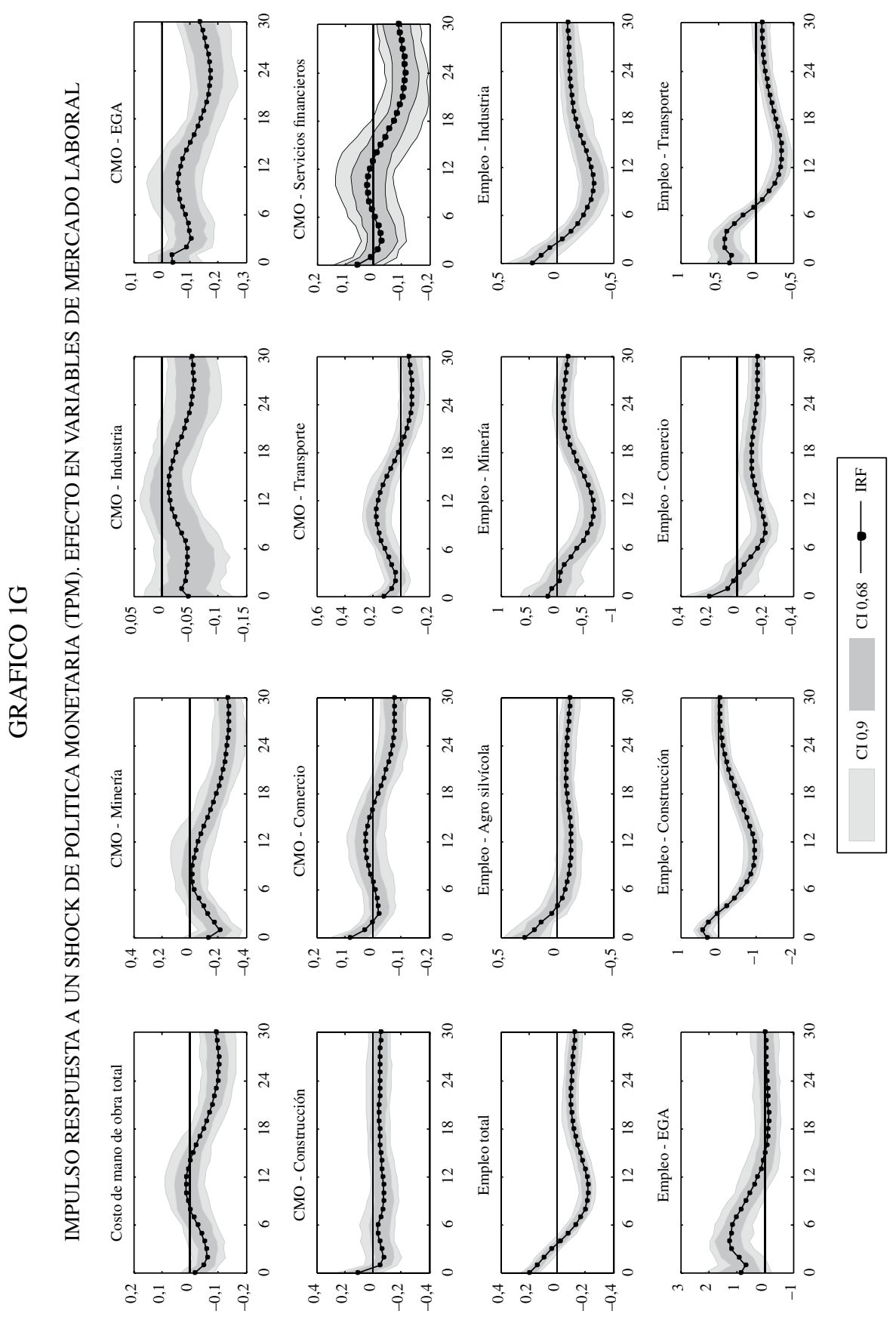




\section{GRAFICO 2A}

IMPULSO RESPUESTA A UN SHOCK DE MERCADO BURSATIL (BOLSA) EFECTO EN VARIABLES MACROECONOMICAS
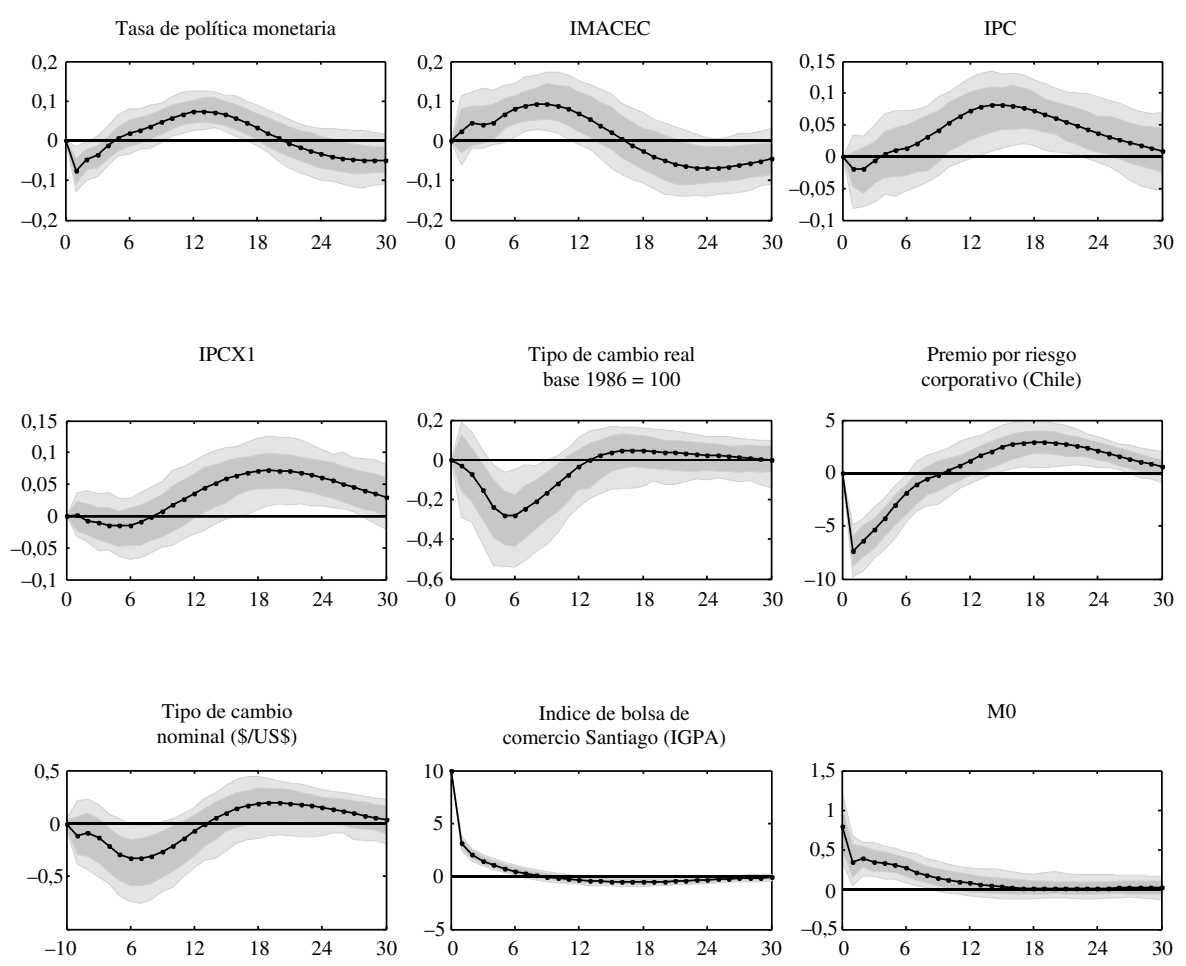

tiene un comportamiento claro, inicialmente no tiene una respuesta fuerte pero luego aumenta, siendo la respuesta máxima del IPC entre los 12 a 18 meses; el caso más notorio se evidencia en el tipo de cambio real (TCR) que se aprecia fuertemente en respuesta al shock, tal cual ha ocurrido en ocasiones en las cuales la bolsa de Santiago presenta ganancias mensuales fuertes. Lo mismo ocurre con el spread corporativo, que disminuye de manera muy fuerte, siendo este una respuesta típica de esta variable en los casos en los cuales se produce un aumento repentino en la bolsa. Por último, en este Gráfico 2a, se observa que la política monetaria tarda en reaccionar en respuesta al aumento en el índice de bolsa, se comporta reaccionando casi de igual manera que la respuesta del IMACEC ante este shock de aumento de riqueza financiera. 
La respuesta de las tasas de colocaciones promedio del sistema financiero (Gráfico 2b), da cuenta de un efecto notable de este shock positivo de riqueza financiera, las tasas nominales de corto plazo reaccionan de manera significativa ante este shock, pero las tasas de largo plazo caen de manera fuerte y significativa, dando a entender un empinamiento marginal en la curva de rendimiento nominal. En tanto, las tasas reales de corto plazo caen de manera fuerte y significativa, mientras que las tasas de largo plazo aumentan fuertemente, en este caso, se puede interpretar que este shock empina la curva de rendimiento de las tasas de interés reales. Las colocaciones promedio del sistema financiero muestran una respuesta persistente ante el shock. También en el Gráfico 2c, se puede observar que las exportaciones aumentan fuertemente y las importaciones caen de manera notable, con esto el shock da cuenta de una mejora en la balanza comercial, aunque la respuesta de las variables de comercio exterior no es significativa y presentan una respuesta de muy baja persistencia.

En el Gráfico 2d se observan las respuestas de las variables de precios, en estas vemos que todas las medidas de IPC subyacentes reaccionan de manera tardía ante el shock, siendo notoria la respuesta después de pasados los doce meses de ocurrido el shock. Las medidas de actividad (Gráfico 2e) presentan algunos puzzles como la caída observada ante este shock de los sectores EGA, comercio, construcción y agro silvícolas. Mientras que las agrupaciones que a priori deberían verse afectadas de manera positiva ante un aumento repentino en la riqueza financiera de la economía, muestran efectivamente respuestas positivas. Dentro de las respuestas de los datos coyunturales (Gráfico 2f) vemos dos puzzles, uno es la caída en la venta de supermercado del INE y en la venta de automóviles, en los demás indicadores como producción y ventas industriales, ventas de comercio minoristas, vemos un aumento fuerte y significativo ante el aumento repentino en la riqueza financiera. Por último, los datos que dan cuenta del mercado laboral (Gráfico 2g) no entregan mucha información sobre la dinámica y la respuesta de estas variables ante el shock financiero del mercado bursátil.

\subsection{Shock de premio por riesgo}

Para el caso del shock de premio por riesgo, asumimos un aumento no anticipado de $100 \mathrm{pb}$ en la prima por riesgo corporativa. Notablemente los resultados de nuestro ejercicio se encuentran en línea con lo obtenido por Uribe y Yue (2006), quienes encuentran que un aumento de $100 \mathrm{pb}$ de premio por riesgo disminuye en a lo más $0,2 \%$ el (PIB) de las economías emergentes y produce una mejora en las exportaciones netas. En nuestro ejercicio (Gráfico 3a) vemos que el IMACEC cae de manera instantánea en alrededor de 0,2\%, en tanto el IPC y el IPCX1 aumentan lentamente hasta llegar a su máximo casi seis meses después de ocurrido el shock. En tanto, el tipo de cambio real y el nominal se deprecian como respuesta a este shock, mientras el índice de bolsa de comercio de Santiago (IGPA) cae fuerte e instantáneamente en casi $15 \%$.

Respecto a la tasa de política monetaria (TPM) vemos que esta se contrae en respuesta al shock hasta casi tres o cuatro meses después del shock, luego aumenta levemente, quizás influida por el aumento en la inflación y la depreciación del tipo de cambio, pero después de nueve meses vuelve a disminuir ya de manera más per- 


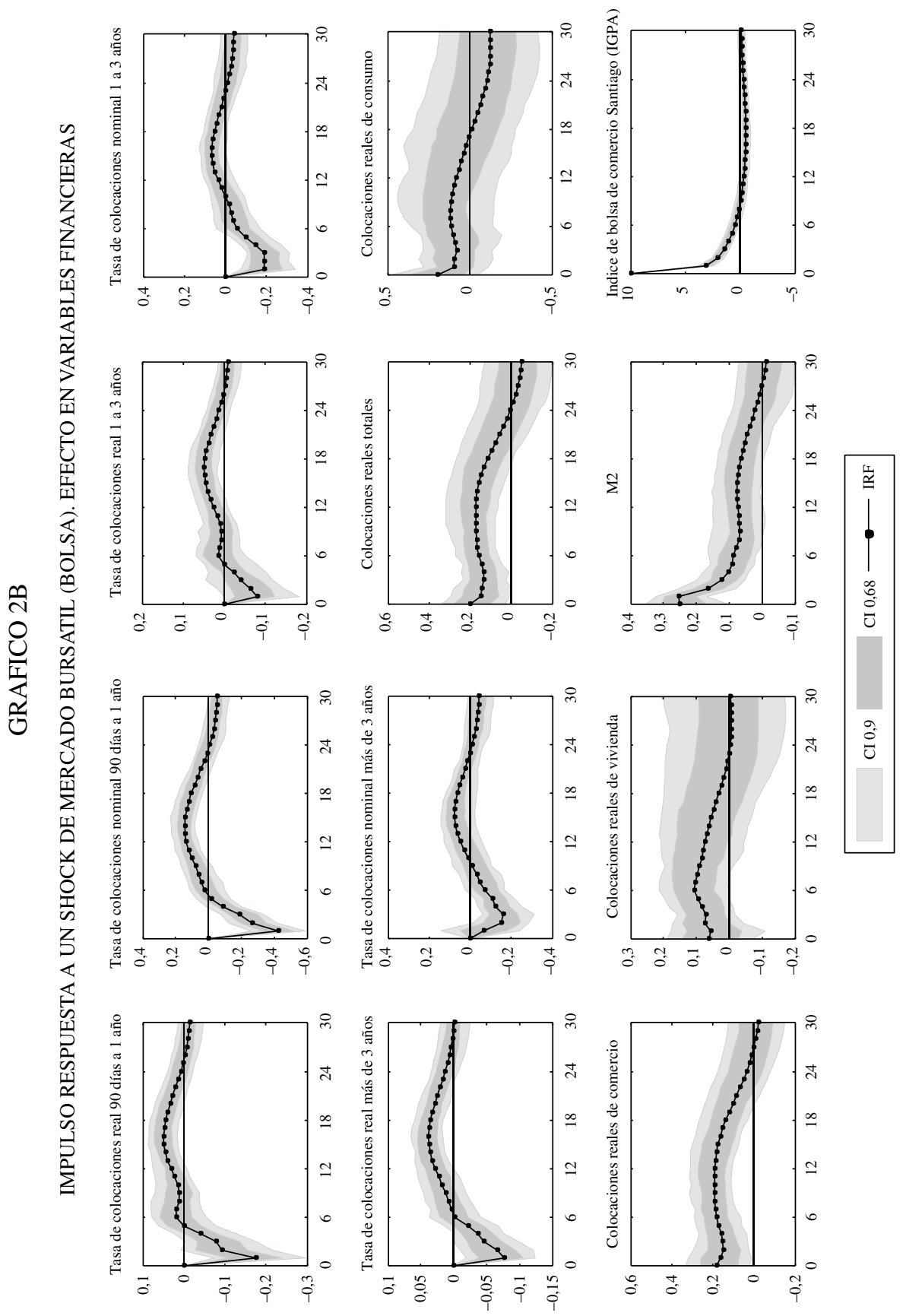




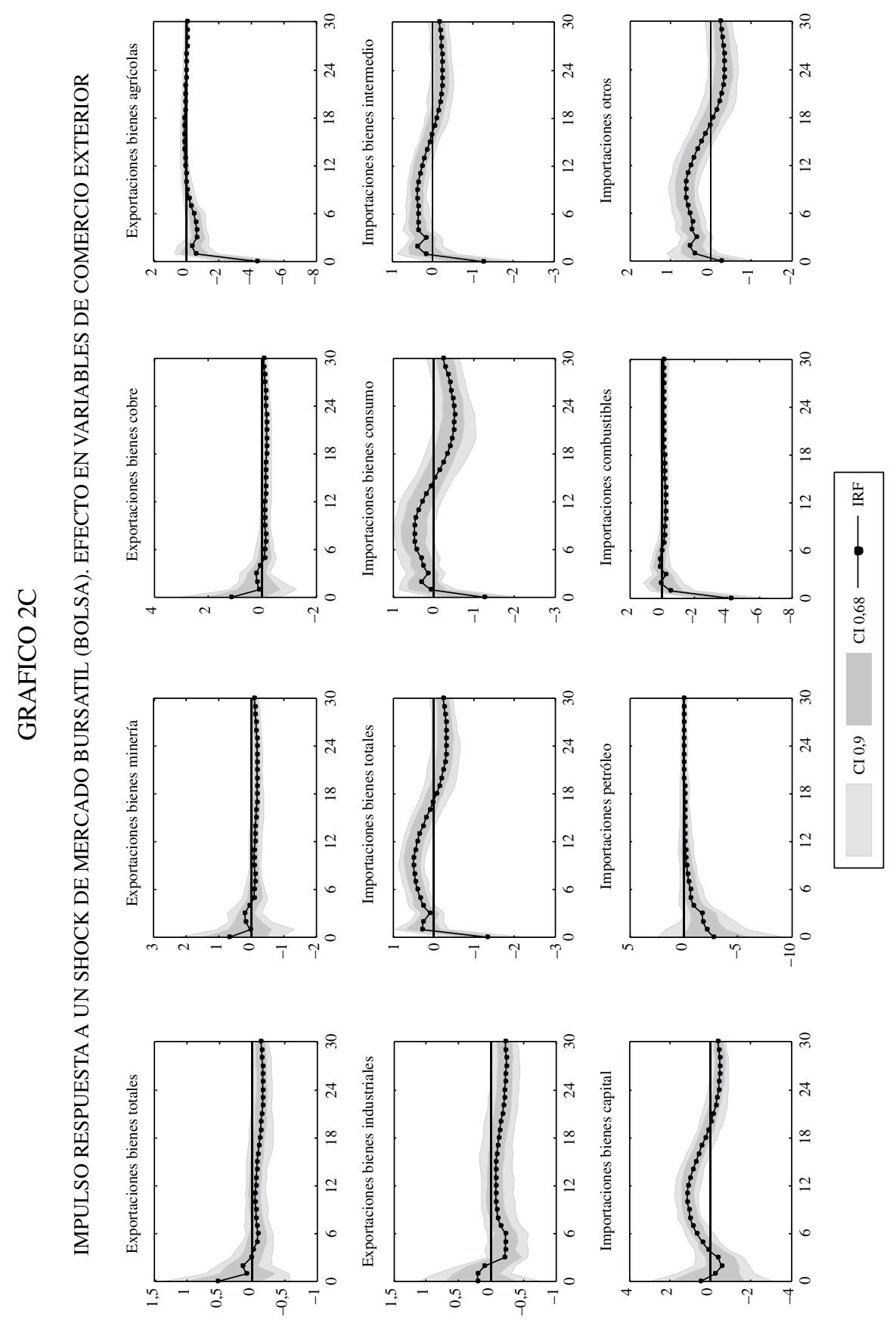




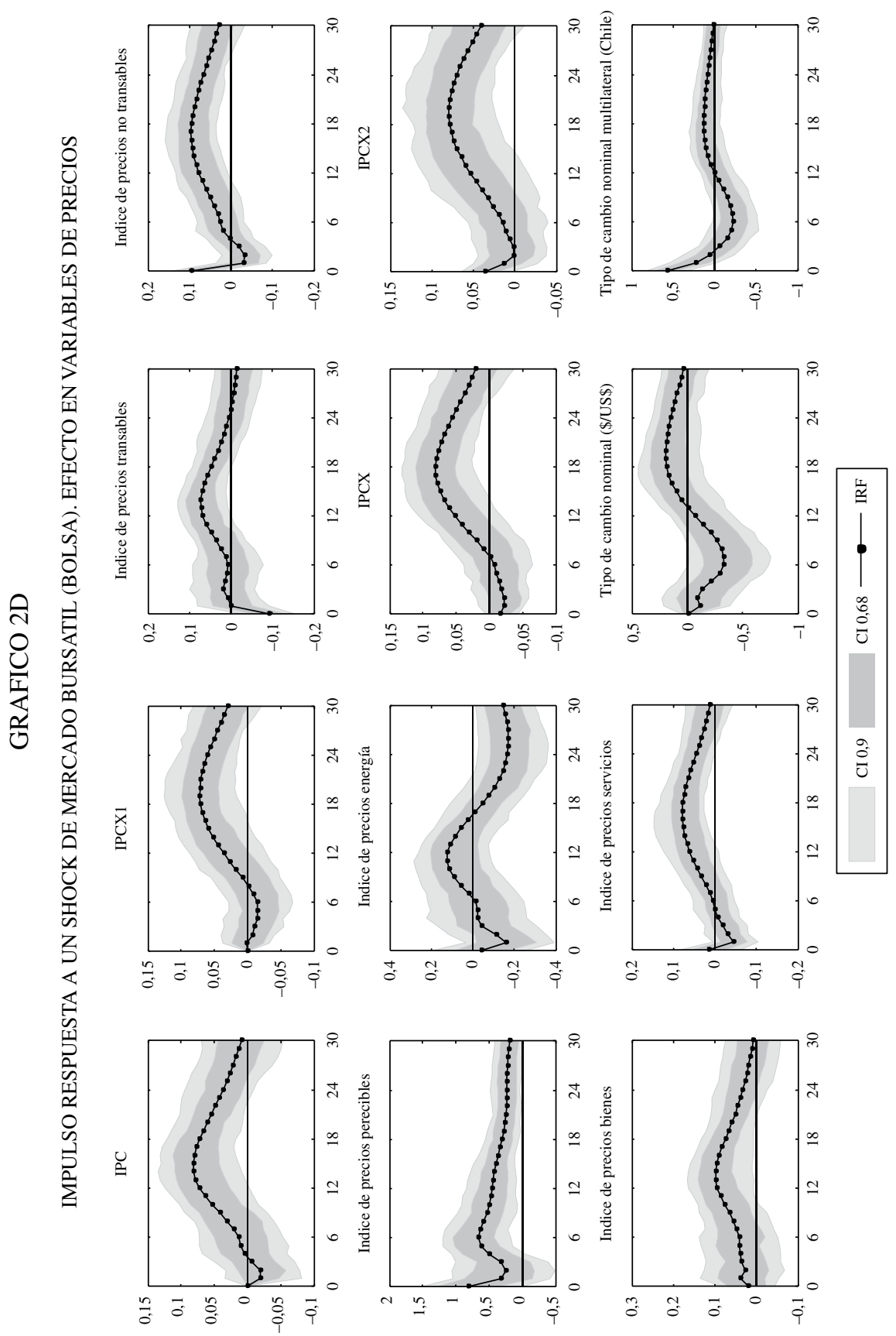




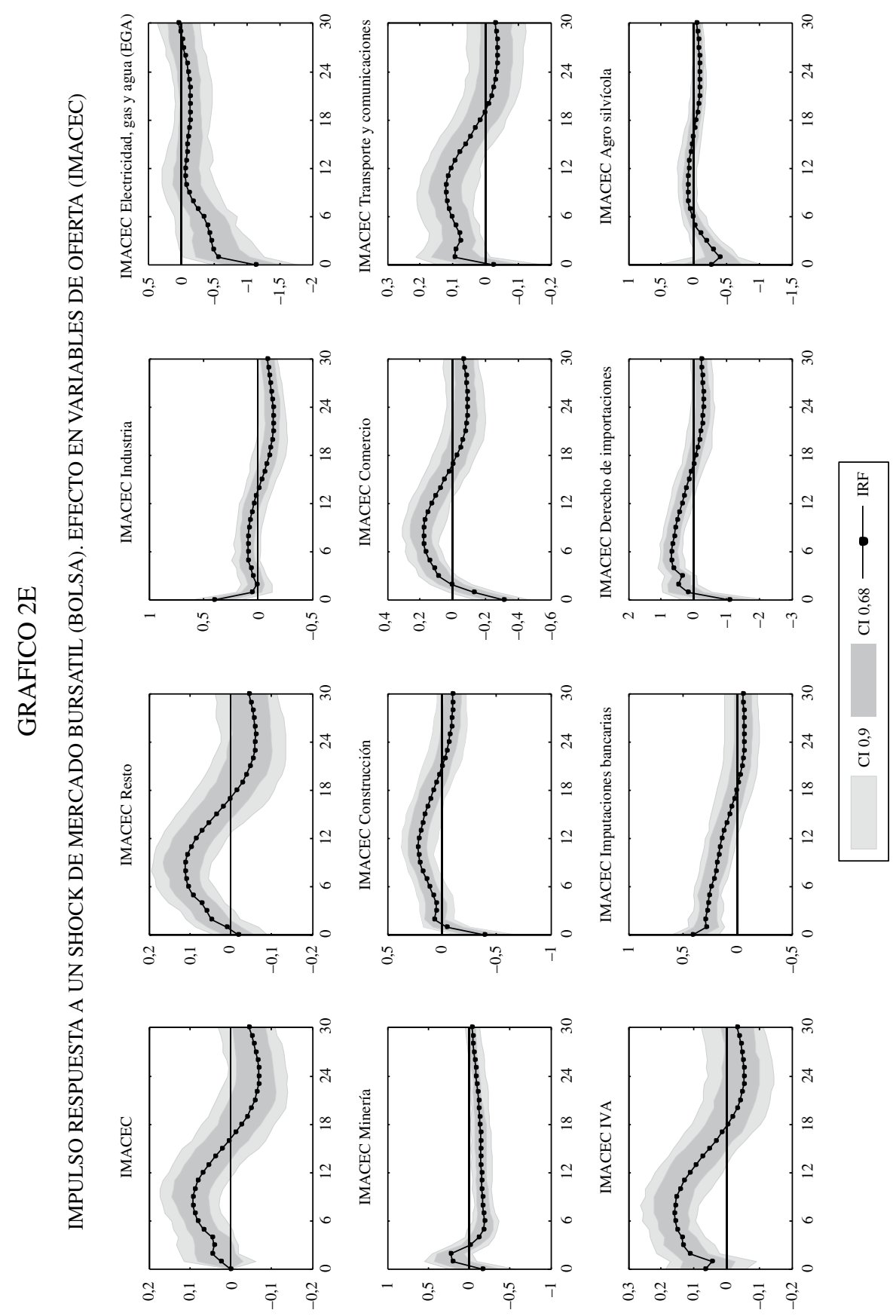




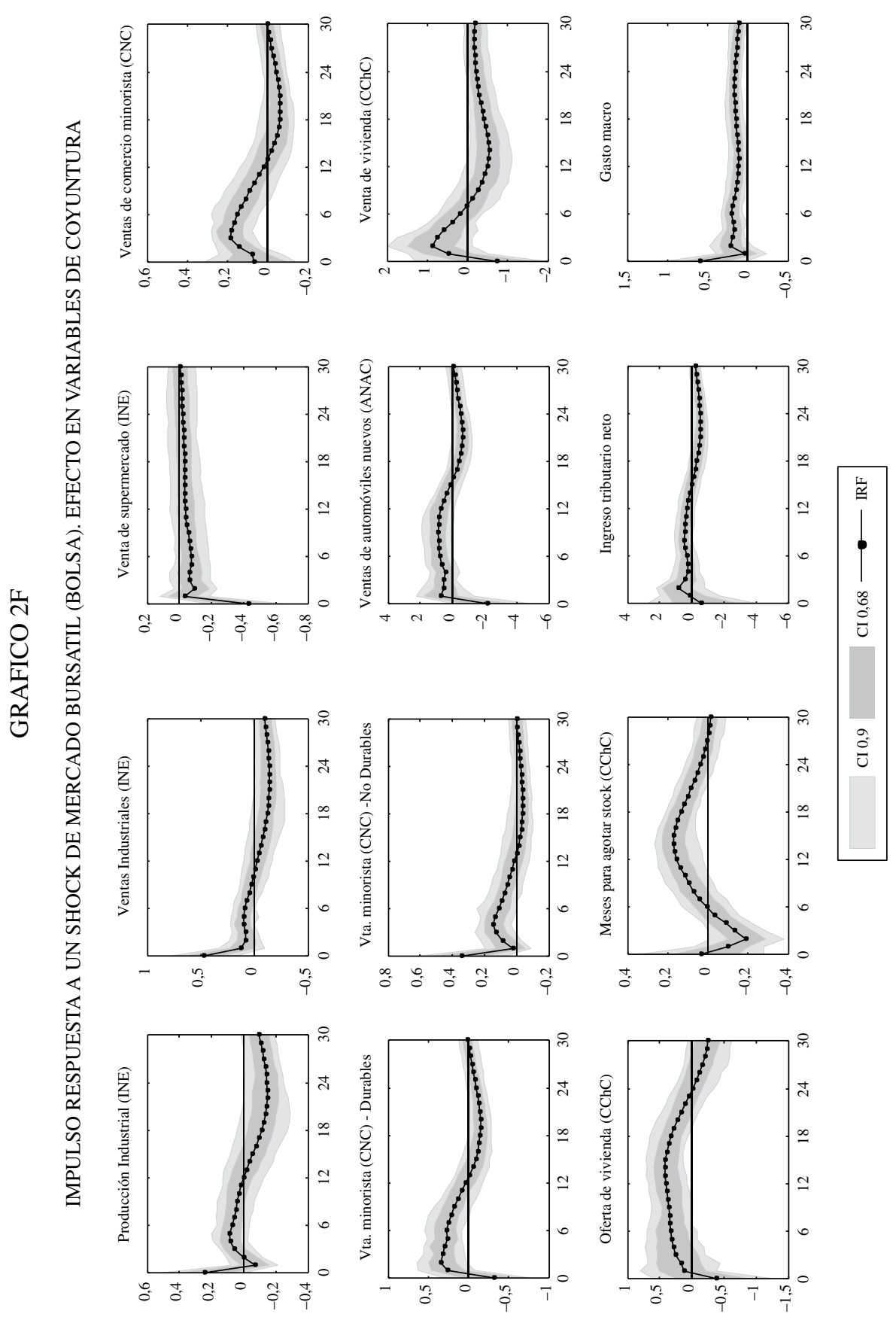



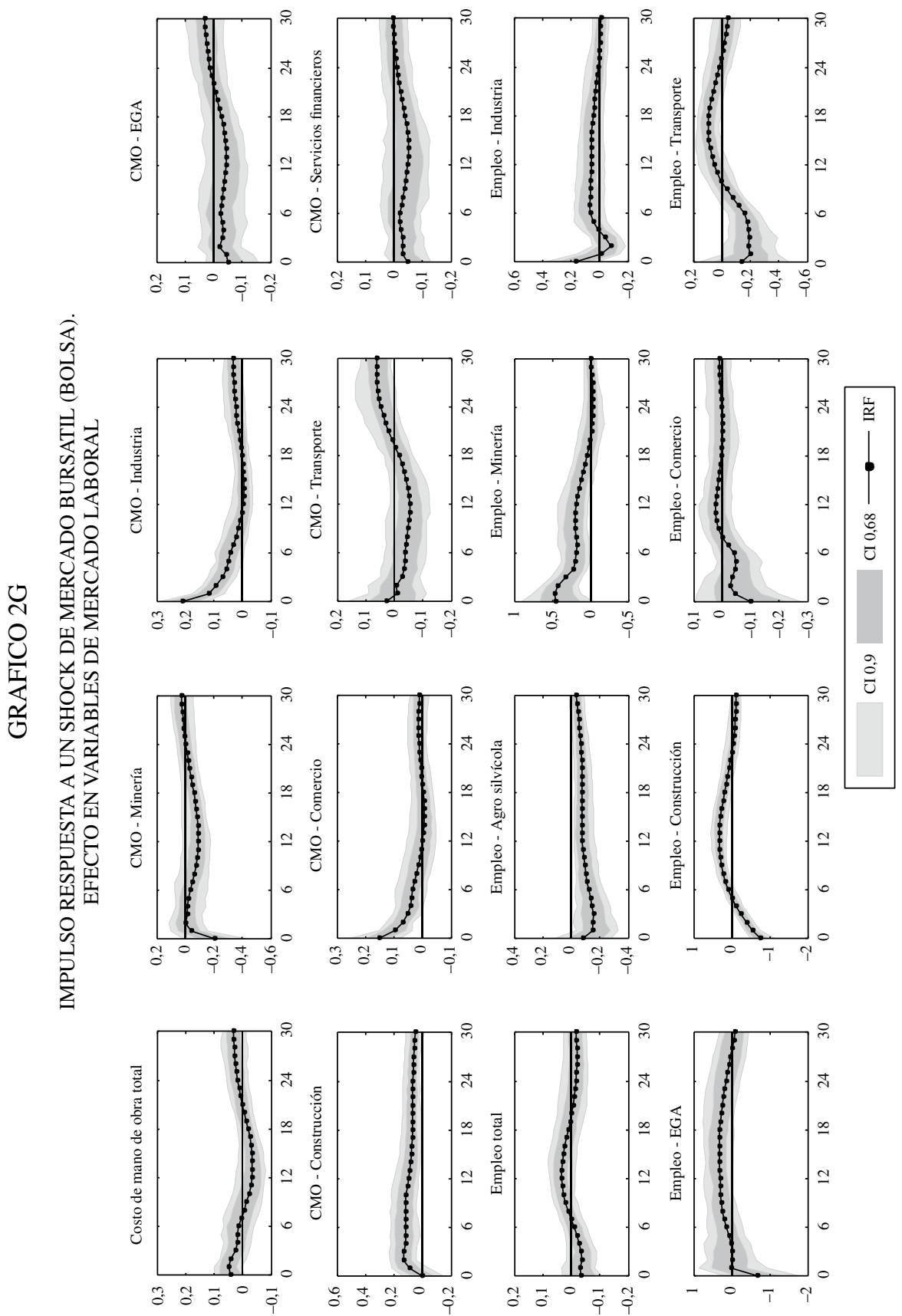


\section{GRAFICO 3A}

IMPULSO RESPUESTA A UN SHOCK DE PREMIO POR RIESGO (SPREAD). EFECTO EN VARIABLES MACROECONOMICAS
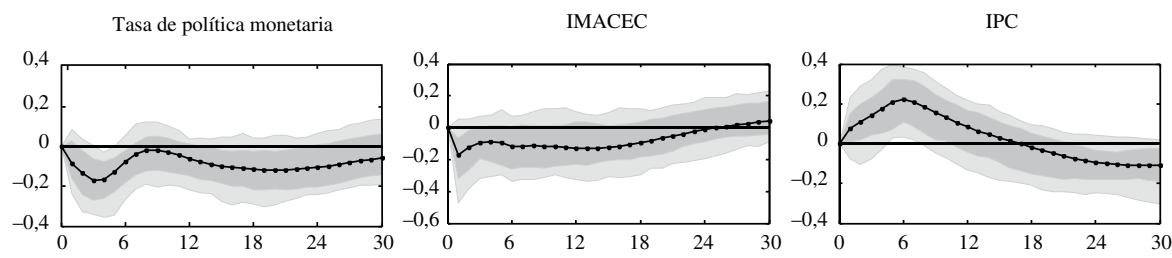

IPCX1
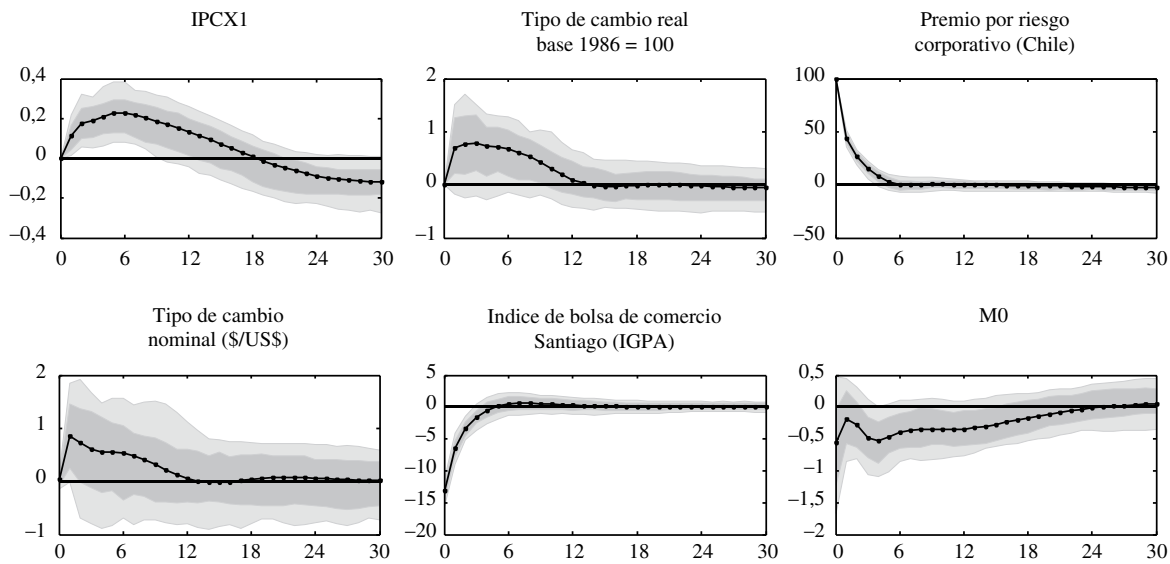

M0

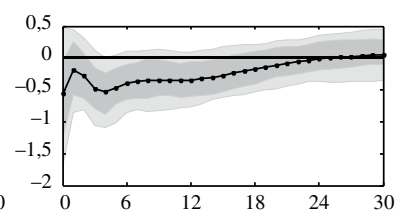

CI 0,9

CI $0,68 \longrightarrow$ IRF

sistente. Sobre las variables financieras (Gráfico 3b), vemos que las tasas de interés de las colocaciones promedio del sistema aumentan en respuesta al shock (resultado similar al encontrado por Uribe y Yue (2006)), las tasas nominales de plazos más cortos reaccionan de manera más fuerte ante el shock en comparación con las tasas de interés reales, en las tasas de plazos mayores a tres años se observa un aumento leve al inicio pero que se disipa rápidamente. El stock de colocaciones reales cae en respuesta al aumento de las primas por riesgo, pero esto es mucho más notorio en las colocaciones de consumo y de comercio, las cuales disminuyen de manera persistente.

Las variables relacionadas al comercio exterior (Gráfico 3c) se contraen rápidamente a consecuencia del shock, pero con muy poca persistencia, en el neto se observa que las importaciones totales caen en mayor magnitud respecto a las exportaciones totales, lo cual nos da a entender una mejora de las exportaciones netas (al igual que Uribe y Yue (2006)); de manera desagregada se puede observar una contracción algo más marcada en las exportaciones industriales, mientras que las importaciones de consumo e intermedio presentan una disminución algo más persistente. 


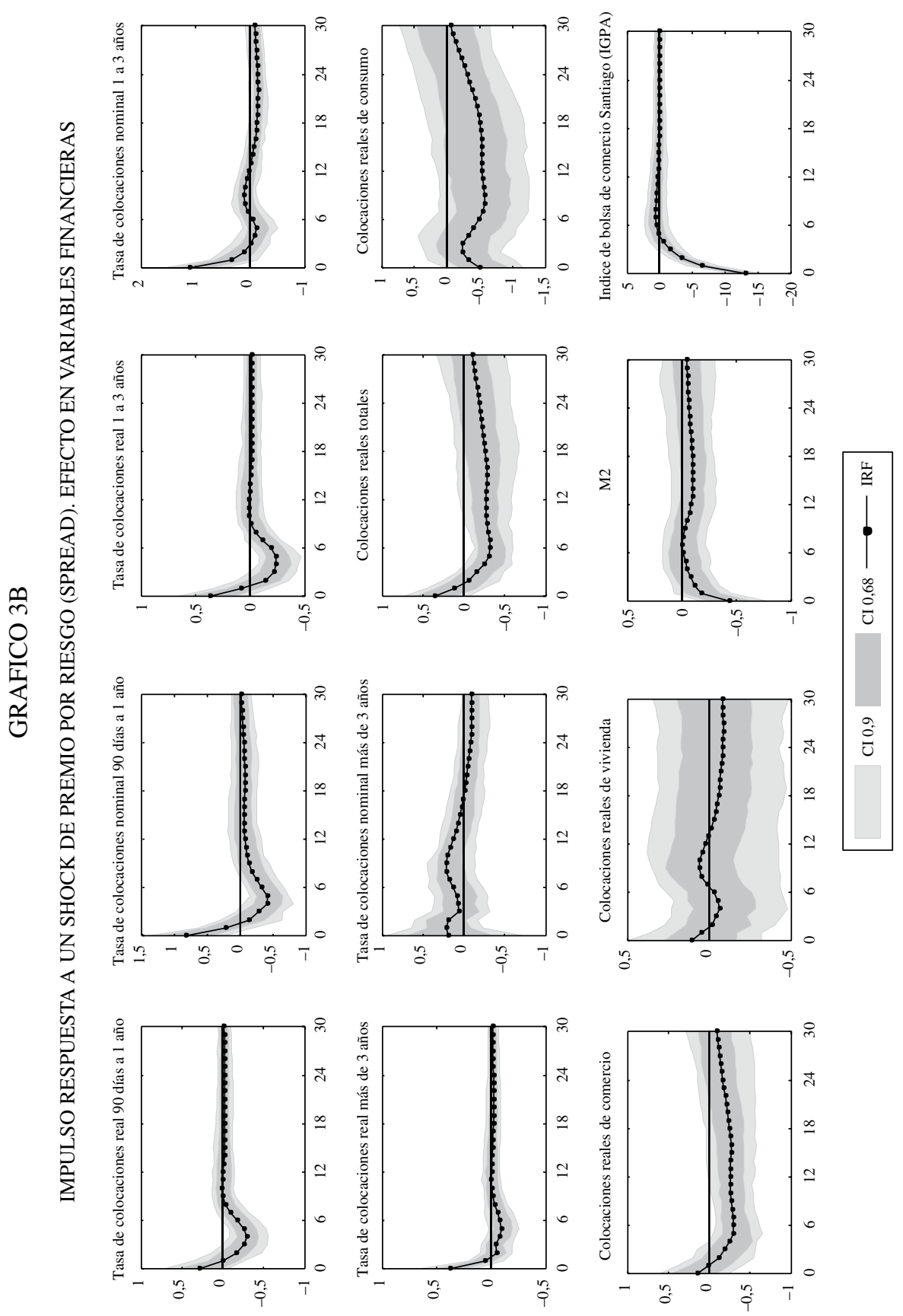




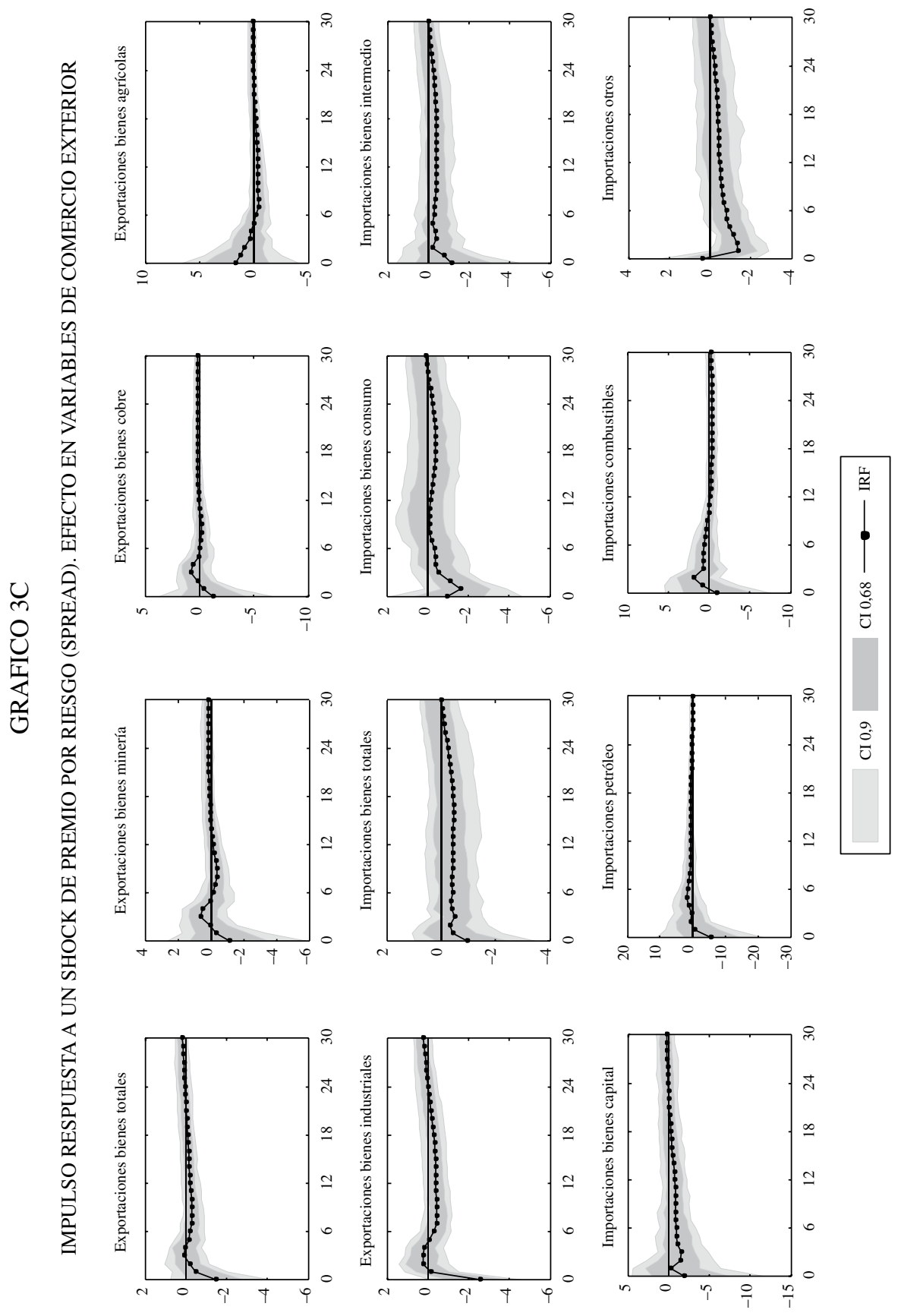


En tanto, las variables de precios (Gráfico 3d) nos dan cuenta de aumentos generalizados en las medidas de índices de precios, tanto en el total como en sus medidas subyacentes, estos aumentan lentamente en respuesta al shock hasta llegar a su máximo casi seis meses después de ocurrido este, el único resultado contra intuitivo se observa en la medida de precios transables y de energía, los cuales disminuyen inicialmente al impacto del shock, luego aumentan llegando a un máximo seis meses después, al igual que los demás índices. Por el lado de las variables que miden la actividad (Gráfico 3e), nos encontramos que las respuesta del IMACEC, el IMACEC Resto, comercio e industria son concordantes, reaccionando en una magnitud y persistencia similar. Las mayores caídas con respecto a este shock se observan en EGA, Minería y Construcción, mientras que en el sector agrosilvícola los derechos de importaciones aumentan a consecuencia del shock, siendo el único puzzle dentro de las variables del IMACEC.

Considerando las variables de coyuntura (Gráfico 3f), vemos que la producción industrial y las ventas industriales del INE retroceden ante el shock de premio por riesgo, la caída es mayor en las ventas industriales, dando a entender un proceso de acumulación de inventarios, este resultado es a consecuencia de los costos de ajuste que presentan las firmas industriales en poder ajustar sus planes de producción ante una caída en las ventas. Similar resultado encontramos al observar las ventas de comercio minoristas de la CNC, las cuales se contraen en mayor medida en los bienes durables que en los no durables, los primeros dan cuenta de una medida que incluyen productos electrónicos y muebles, mientras que los últimos dan cuenta de bienes de consumo habitual que típicamente presentan un mayor hábito, por ende estos reaccionan en menor medida respecto a los bienes durables. La respuesta más fuerte se presenta en las ventas de automóviles nuevos (ANAC), contrayéndose en aproximadamente un $10 \%$ en respuesta al shock y se deshaciéndose casi seis meses después, esto es intuitivo debido a que el shock de premio por riesgo tiene como consecuencia una fuerte contracción de la liquidez y una depreciación del tipo de cambio; estas variables afectan en mayor medida el proceso de acumulación de bienes durables de las familias. Las variables relacionadas al mercado inmobiliario, ventas y oferta de viviendas no tienen una respuesta clara al shock. Por último, las variables del mercado laboral (Gráfico 3g), nos dan cuenta que los costos de mano de obra (CMO) caen en respuesta al shock de premio por riesgo; el mayor efecto se observa en industria, construcción y servicios financieros, mientras la respuesta del empleo no es clara, aunque el empleo en minería parece contraerse en respuesta al shock.

\section{CONCLUSION}

En este documento se evalúa el desempeño de los VAR' bayesianos de diferentes tamaños. Se toman en cuenta las especificaciones estándares en la literatura con 5, 11 , 38, 50, 58, 73, 97 y 116 variables; desde el VAR con 31 variables, vamos analizando progresivamente información sectorial y coyuntural, junto con datos duros que son considerados fundamentales dentro de la literatura macroeconómica. Se fijaron los priors siguiendo la literatura estándar respecto a los VAR's bayesianos, excepto que el 


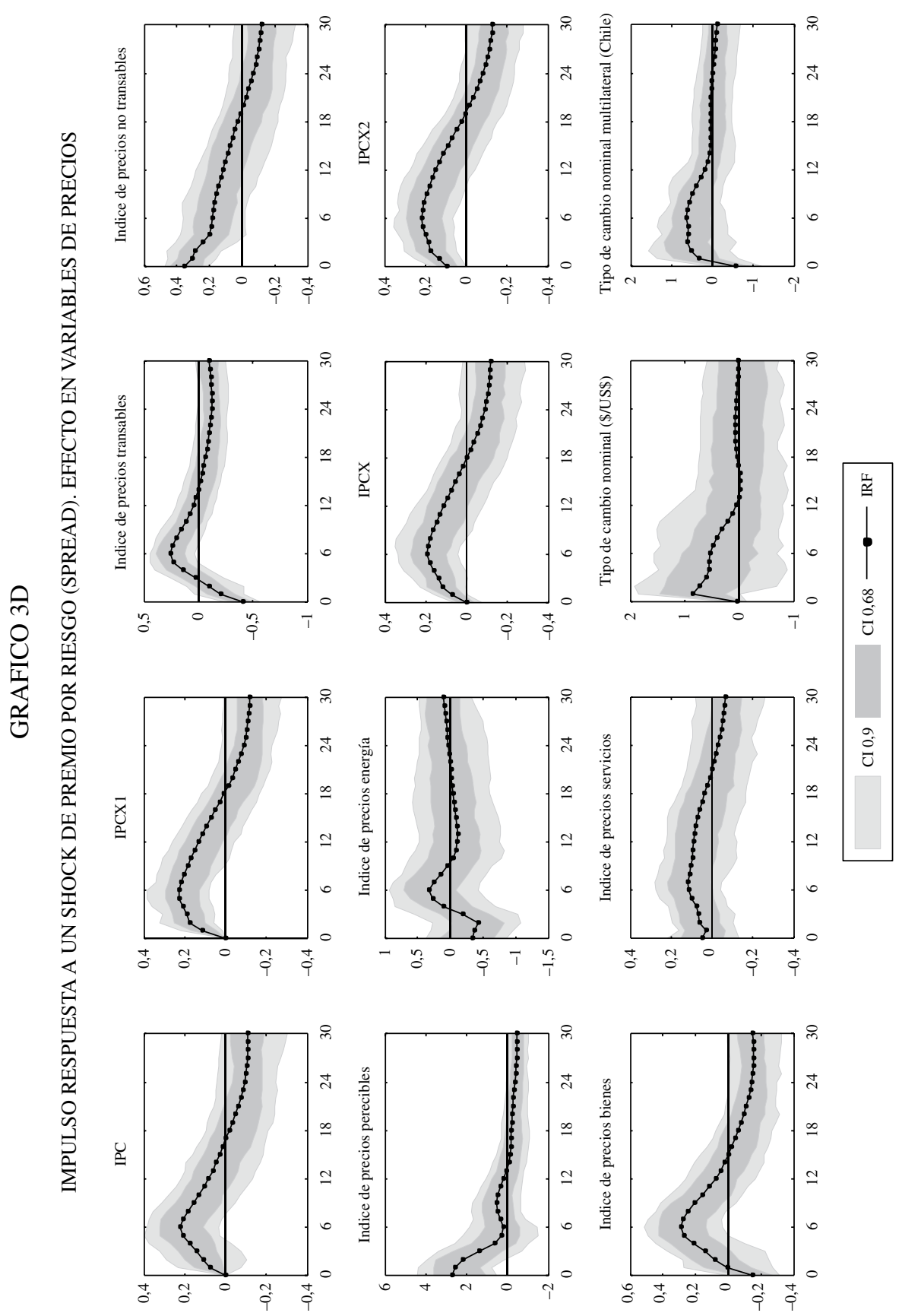




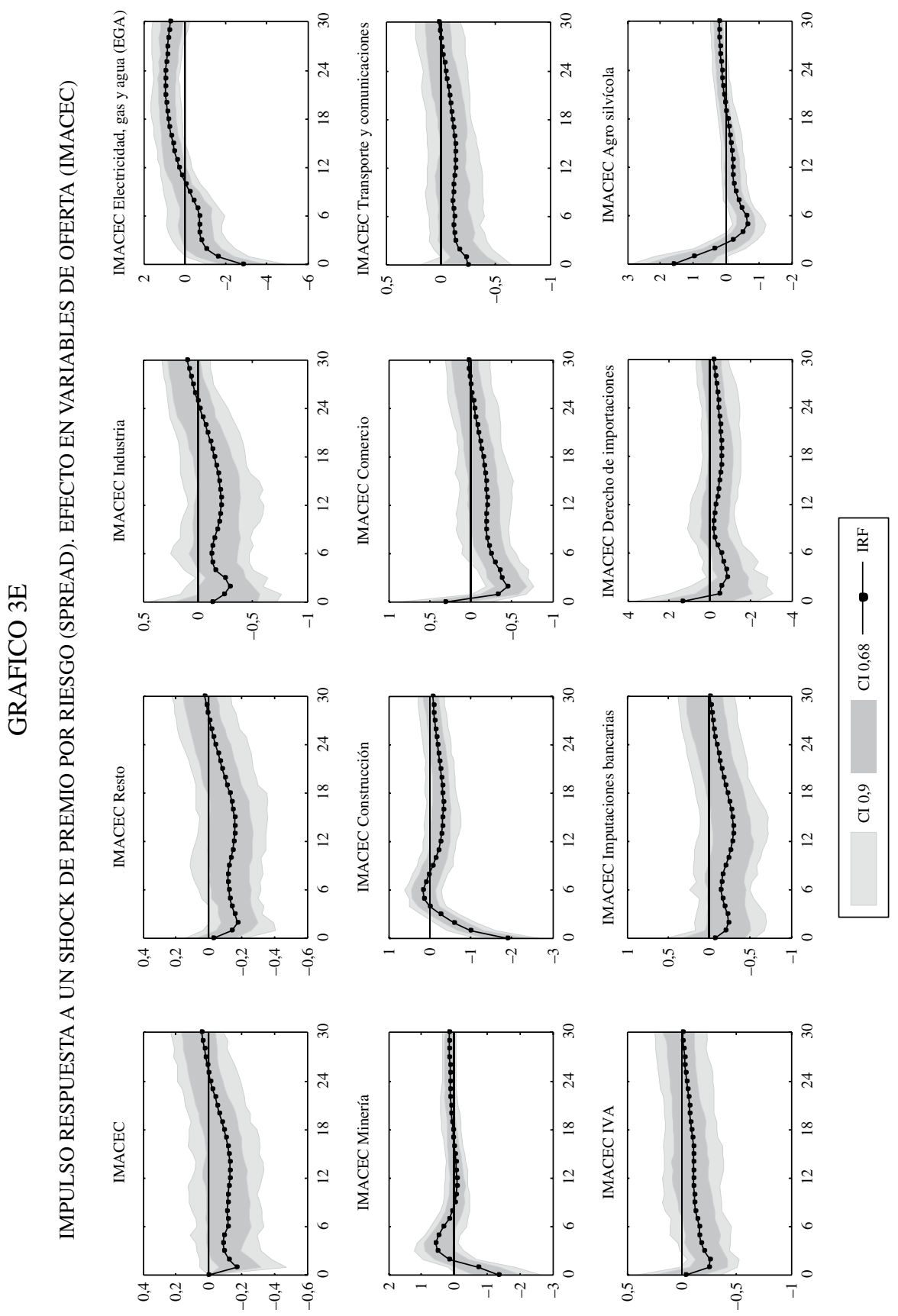




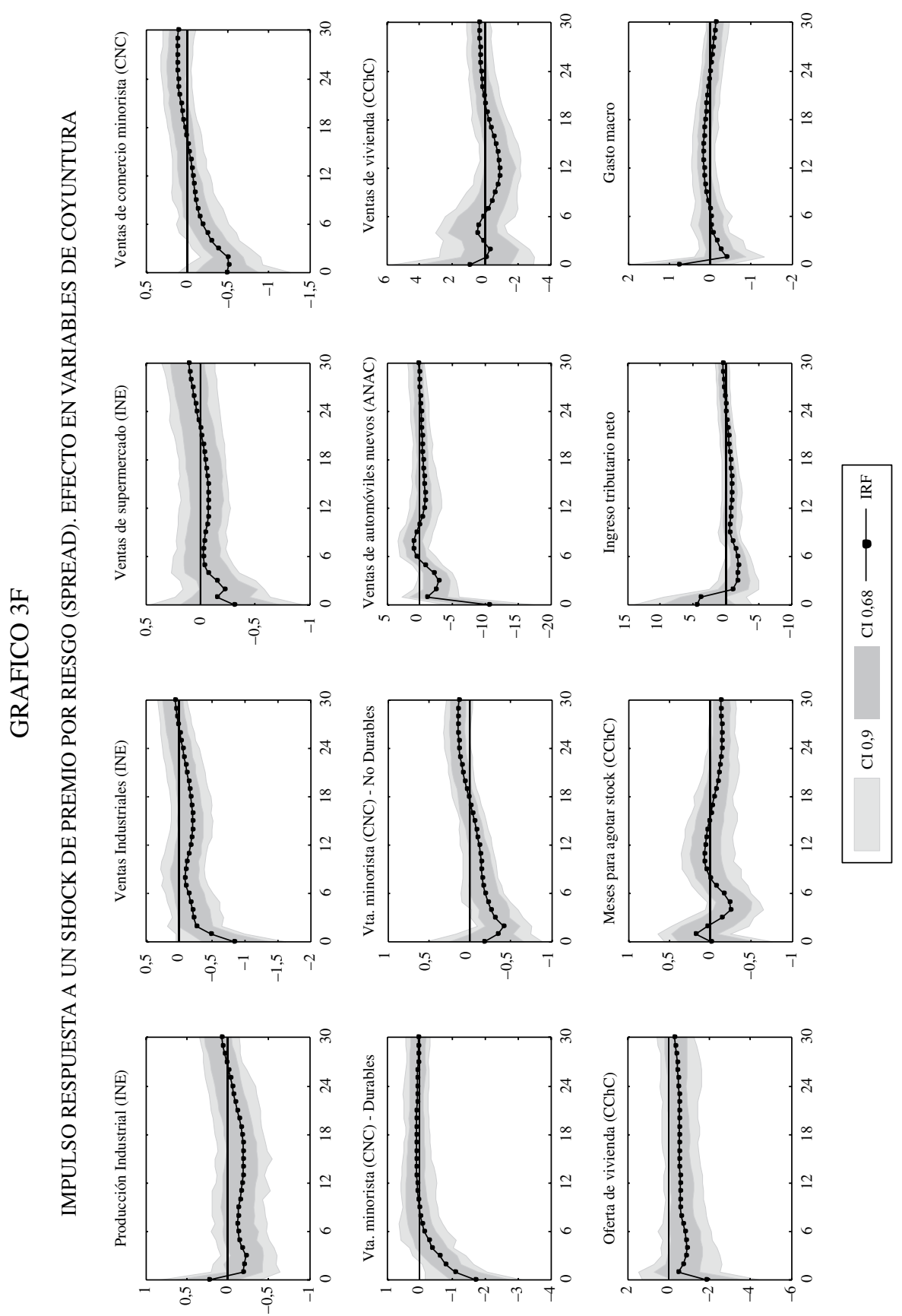




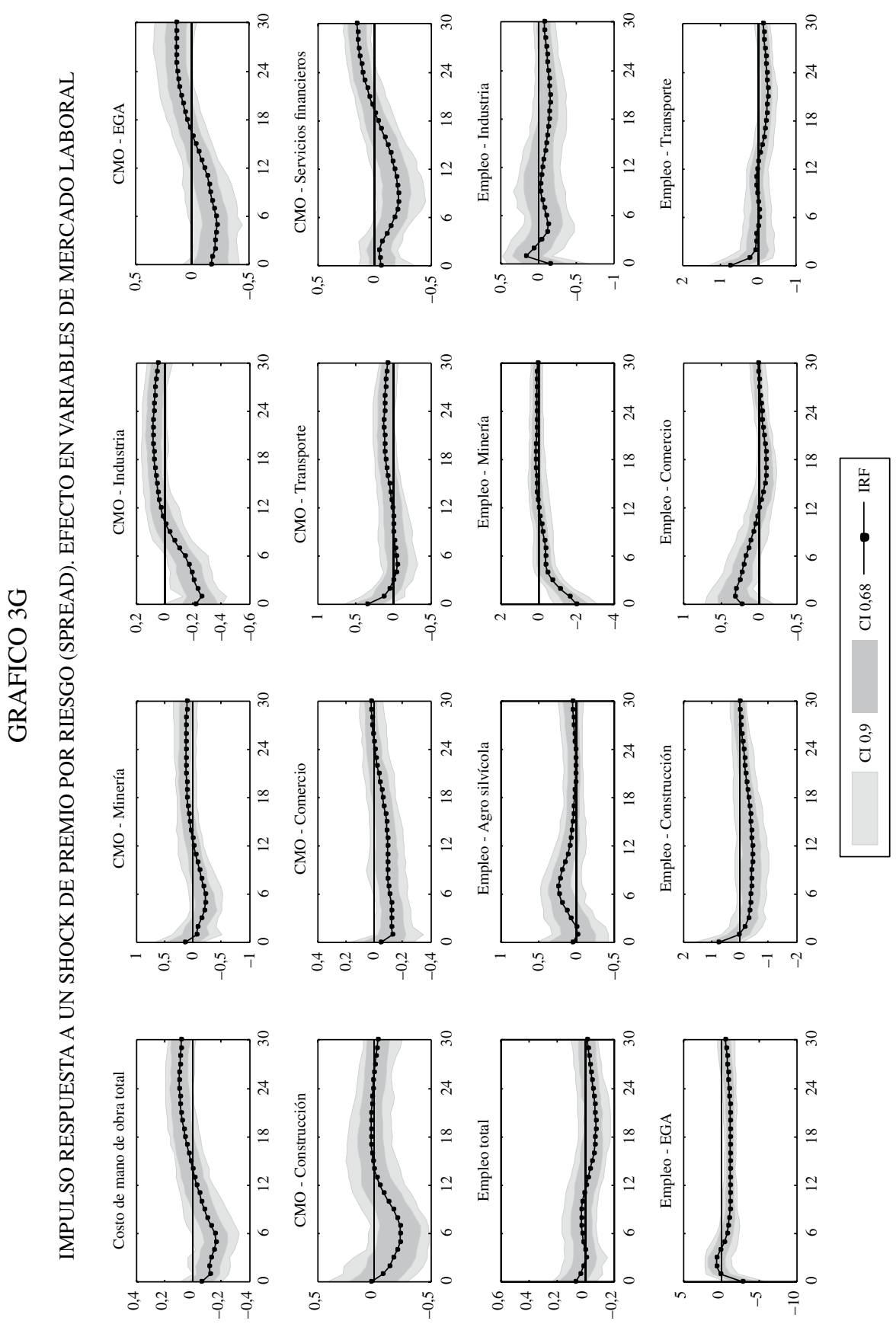


híper parámetro que controla el ajuste general (overall tightness) se fija de acuerdo al tamaño del modelo, siguiendo el algoritmo propuesto por Banbura, Giannone y Reichlin (2010) y modificado por Bloor y Matherson (2008), en nuestro caso minimizando el error de pronóstico relativo del indicador de actividad económica (IMACEC), índice de precios al consumidor (IPC) y la tasa de política monetaria (TPM).

Esos resultados indican que el VAR bayesiano constituye una herramienta apropiada para lidiar con los grandes paneles que implica el set de información que se encuentra disponible para el macroeconomista. También se muestra que VAR bayesiano con más de 100 variables es factible y que además produce mejores pronósticos que un VAR simple típicamente considerado dentro de la literatura.

Se ha analizado la exactitud de predicción de las distintas especificaciones y realizado el análisis estructural de los efectos de un shock de política monetaria y un shock del mercado bursátil. En el análisis del shock de política monetaria se muestra como se propagan los efectos de este a través de canales no tradicionales, como las variables financieras, sectores del IMACEC y del IPC, y también en variables de coyuntura. Estos resultados son coherentes y robustos a pesar de la gran cantidad de datos considerados. Respecto al shock bursátil y de premio por riesgo, vemos que este entrega buenos resultados, demostrando la utilidad del gran VAR bayesiano para el análisis de los efectos de distintos shocks no tradicionales dentro de la literatura.

\section{BIBLIOGRAFIA}

AGUIRRE, A.R. y L.F. CESPEDES (2004). "Uso de Análisis Factorial Dinámico para Proyecciones Macroeconómicas", Working Papers Central Bank of Chile 274, Central Bank of Chile.

ANGELINI, E., G. CAMBA-MENDEZ, D. GIANNONE, G. RÜNSTLER y L. REICHLIN (2008). "Short-term forecasts of euro area GDP growth", Working Paper Series 949, European Central Bank.

BANBURA, M., D. GIANNONE y L. REICHLIN (2010). "Large Bayesian vector auto regressions", Journal of Applied Econometrics 25(1), pp. 71-92.

BERNANKE, B., J. BOIVIN y P.S. ELIASZ (2005). "Measuring the Effects of Monetary Policy: A Factor-augmented Vector Autoregressive (FAVAR) Approach", The Quarterly Journal of Economics 120(1), pp. 387-422.

BLOOR, C. y T. MATHERSON (2008). "Analysing shock transmission in a data-rich environment: A large BVAR for New Zealand”, Reserve Bank of New Zealand Discussion Paper Series DP2008/09, Reserve Bank of New Zealand.

BOIVIN, J. y S. NG (2003). “Are More Data Always Better for Factor Analysis?”, NBER Working Papers 9829, National Bureau of Economic Research, Inc.

BOIVIN, J. y M. GIANNONI (2008). “Global Forces and Monetary Policy Effectiveness”, NBER Working Papers 13736, National Bureau of Economic Research, Inc.

BRAVO, H.L., C. GARCIA, V. MIES y M. TAPIA (2003). "Heterogeneidad de la Transmisión Monetaria: Efectos Sectoriales y Regionales”, Journal Economía Chilena 6(3), pp. 5-26.

BRAVO, H.L. y C. GARCIA (2002). "Measuring Monetary Policy and Pass-Through in Chile", Journal Economía Chilena 5(3), pp. 5-28.

CAMACHO, M. y G. PEREZ-QUIROZ (2009). "Ñ-STING: España Short Term Indicator of Growth”, Banco de España Working Papers 0912, Banco de España.

CAMACHO, M. y G. PEREZ-QUIROZ (2010). "Introducing the euro-sting: Short-term indicator of euro area growth”, Journal of Applied Econometrics 25(4), pp. 663-694.

CANOVA, F. (1991). "The Sources of Financial Crisis: Pre- and Post-Fed Evidence", International Economic Review 32(3), pp. 689-713.

CHRISTIANO, L.J., M. EICHENBAUM y C.L. EVANS (2005). "Nominal Rigidities and the Dynamic Effects of a Shock to Monetary Policy", Journal of Political Economy 113(1), pp. 1-45. 
CHRISTIANO, L., C.L. ILUT, R. MOTTO y M. ROSTAGNO (2010). "Monetary Policy and Stock Market Booms", NBER Working Papers 16402, National Bureau of Economic Research, Inc.

DE MOL, C., D. GIANNONE y L. REICHLIN (2008). "Forecasting using a large number of predictors: Is Bayesian shrinkage a valid alternative to principal components?", Journal of Econometrics 146(2), pp. 318-328.

DIEBOLD, F. and R. MARIANO (1995). "Comparing Predictive Accuracy", Journal of Business \& Economic Statistics 13(3), pp. 253-263.

DOAN, T., R. LITTERMAN y C. SIMS (1984). "Forecasting and conditional projection using realistic prior distributions", Econometric Reviews 3(1), pp. 1-100.

ECHAVARRIA, G. y W. GONZALEZ (2011). "Un Modelo de Factores Dinámicos de Pequeña Escala para el Imacec", Notas de Investigación Journal Economía Chilena 14(2), pp. 109-118.

FORNI, M., M. HALLIN, M. LIPPI y L. REICHLIN (2005). "The Generalized Dynamic Factor Model: OneSided Estimation and Forecasting", Journal of the American Statistical Association 100, pp. 830-840.

FORNI, M., M. HALLIN, M. LIPPI y L. REICHLIN (2000). "The Generalized Dynamic-Factor Model: Identification and Estimation", The Review of Economics and Statistics 82(4), pp. 540-554.

FRALE, C., M. MARCELLINO, G.L. MAZZI y T. PROIETTI (2008). "A Monthly Indicator of the Euro Area GDP", Economics Working Papers ECO2008/32, European University Institute.

GARCIA, C.J., P. GONZALEZ y A. MONCADO (2010). "Proyecciones macroeconómicas en Chile: una aproximación estructural y bayesiana", Ilades Universidad Alberto Hurtado, Documento de Trabajo I-262.

GORDON, D.B. y E. LEEPER (1994). "The Dynamic Impacts of Monetary Policy: An Exercise in Tentative Identification", Journal of Political Economy 102(6), pp. 1228-1247.

HENDRY, D.F. y K. HUBRICH (2010). "Combining disaggregate forecasts or combining disaggregate information to forecast an aggregate", Working Paper Series 1155, European Central Bank.

JARAMILLO, P. (2008). "Estimación de Var Bayesianos para la Economía Chilena", Working Papers Central Bank of Chile 508, Central Bank of Chile.

KADIYALA, K. R. y S. KARLSSON (1997). "Numerical Methods for Estimation and Inference in Bayesian VAR-Models", Journal of Applied Econometrics 12(2), pp. 99-132.

LITTERMAN, R. (1986). "Forecasting with Bayesian Vector Autoregressions-Five Years of Experience", Journal of Business \& Economic Statistics 4(1), pp. 25-38.

MARIANO, R.S. y Y. MURASAWA (2003). "A new coincident index of business cycles based on monthly and quarterly series", Journal of Applied Econometrics 18(4), pp. 427-443.

MEDINA, J.P. y C. SOTO (2007). "The Chilean Business Cycles Through the Lens of a Stochastic General Equilibrium Model”, Working Papers Central Bank of Chile 457, Central Bank of Chile.

MILANI, F. (2011). "The impact of foreign stock markets on macroeconomic dynamics in open economies: A structural estimation", Journal of International Money and Finance 30(1), pp. 111-129.

PARRADO, E.H. (2001). "Foreign Shocks and Monetary Policy Transmission in Chile", Journal Economía Chilena 4(3), pp. 29-57.

ROBERTSON, J.C. y E.W. TALLMAN (1999). "Vector autoregressions: forecasting and reality", Economic Review, Federal Reserve Bank of Atlanta Q1, pp. 4-18.

SIMS, C.A. (1993). "A Nine-Variable Probabilistic Macroeconomic Forecasting Model”, NBER Chapters, in: Business Cycles, Indicators and Forecasting, pp. 179-212 National Bureau of Economic Research, Inc.

SIMS, C.A. y T. ZHA (1998). "Bayesian Methods for Dynamic Multivariate Models", International Economic Review 39(4), pp. 949-968.

STOCK, J.H. y M.W. WATSON (2002). "Macroeconomic Forecasting Using Diffusion Indexes”, Journal of Business \& Economic Statistics 20(2), pp. 147-162.

STOCK, J.H. y M.W. WATSON (2005). "Implications of Dynamic Factor Models for VAR Analysis", NBER Working Papers 11467, National Bureau of Economic Research, Inc.

STOCK, J.H. y M.W. WATSON (1999). "Forecasting inflation", Journal of Monetary Economics 44(2), pp. 293-335.

URIBE, M. y V.Z. YUE (2006). “Country spreads and emerging countries: Who drives whom?”, Journal of International Economics 69(1), pp. 6-36 


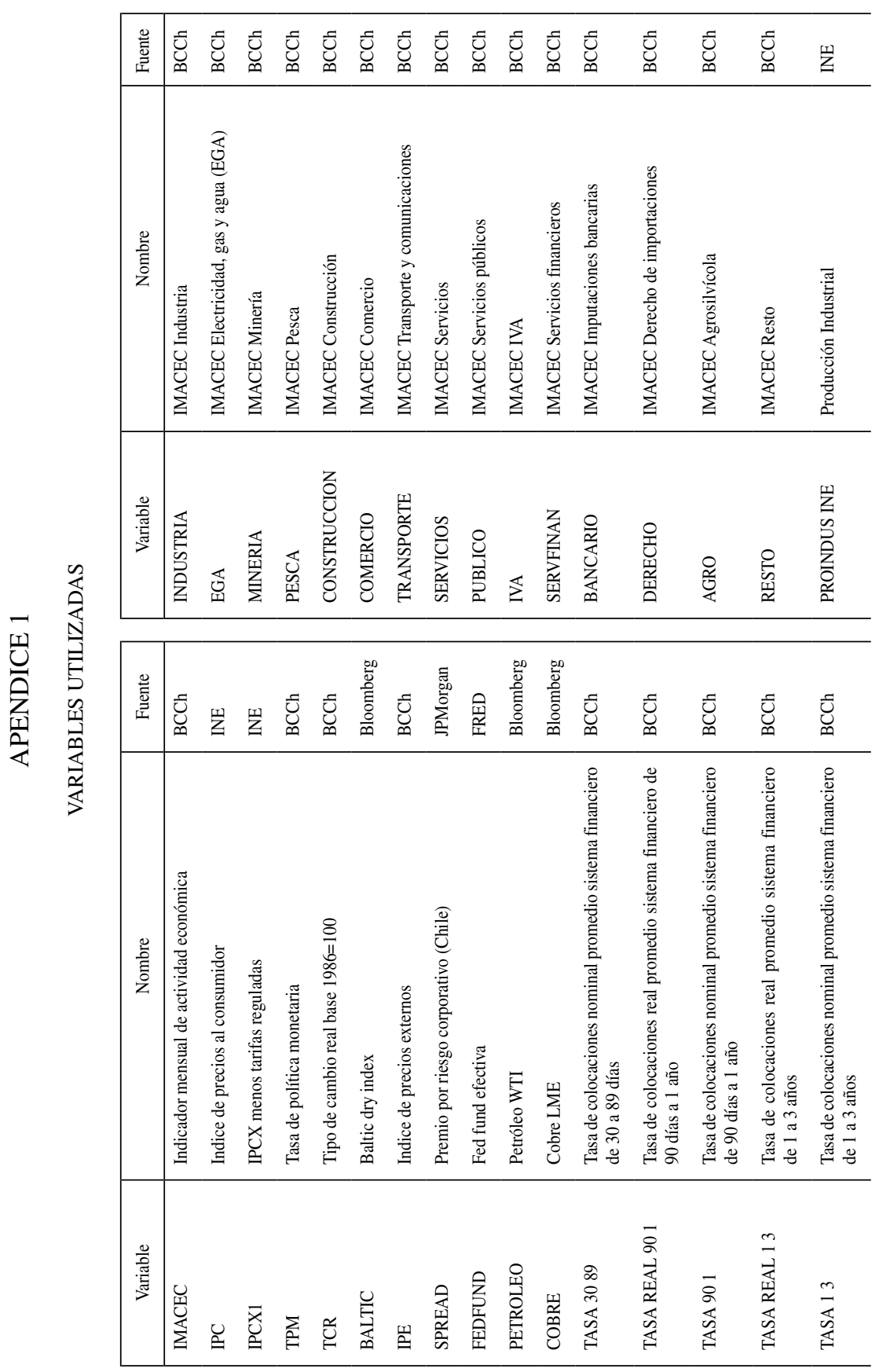




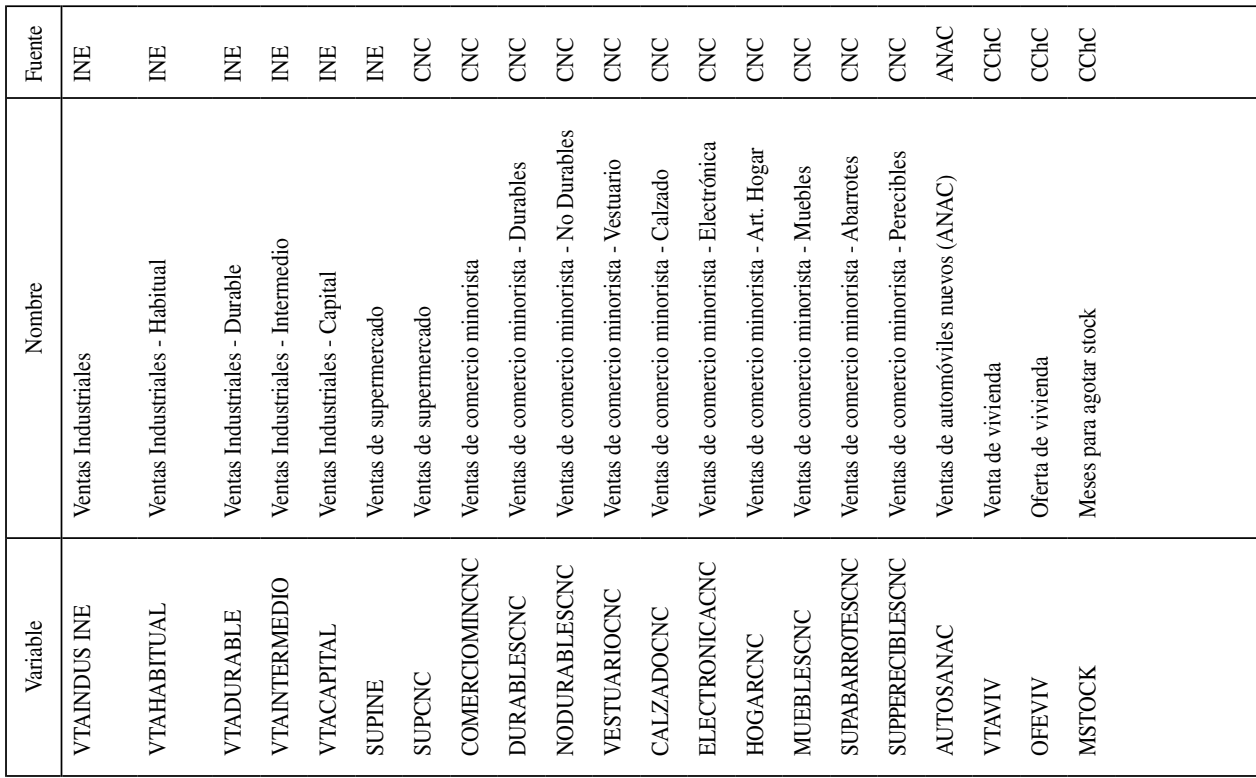

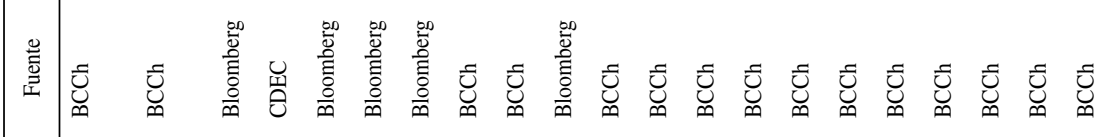




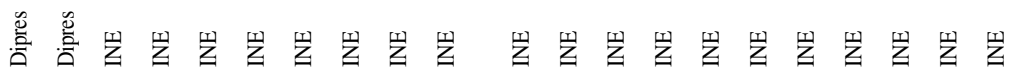

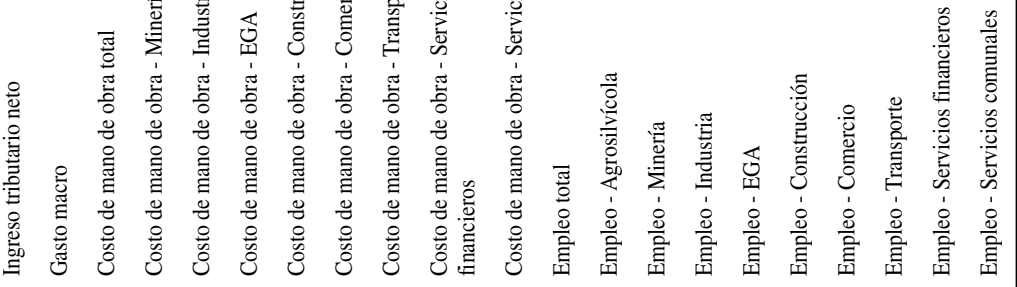

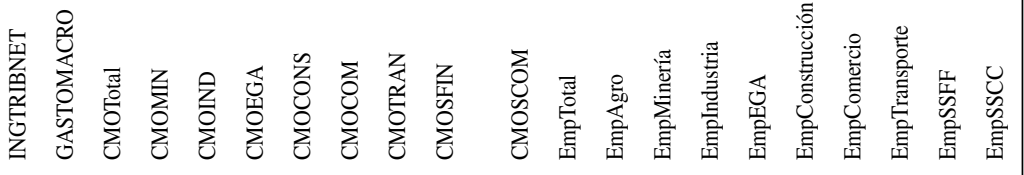

E

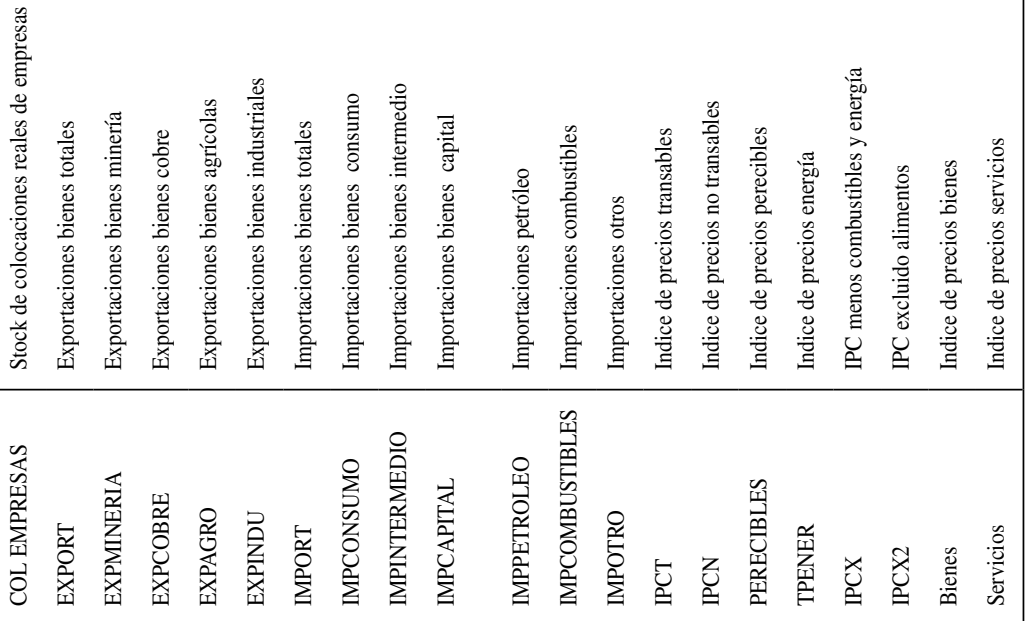


